\title{
Structural Reliability Analysis of Wind Turbines:
} A Review

\author{
Zhiyu Jiang ${ }^{1,2}$ (D) $^{\text {, Weifei Hu }}{ }^{3}{ }^{(1)}$, Wenbin Dong ${ }^{4}$ (D), Zhen Gao ${ }^{1,2,5}$ and Zhengru Ren ${ }^{1,2,5, *}$ \\ 1 Department of Marine Technology, Norwegian University of Science and Technology (NTNU), \\ NO-7491 Trondheim, Norway; zhiyu.jiang@ntnu.no (Z.J.); Zhen.gao@ntnu.no (Z.G.) \\ 2 Centre for Research-Based Innovation of Marine Operations (SFI MOVE), Norwegian University of Science \\ and Technology (NTNU), NO-7491 Trondheim, Norway \\ 3 Sibley School of Mechanical and Aerospace Engineering, Cornell University, Ithaca, NY 14853, USA; \\ wh348@cornell.edu \\ 4 DNV GL, P.O. Box 300, 1322 Høvik, Norway; Wenbin.Dong@dnvgl.com \\ 5 Centre for Autonomous Marine Operations and Systems (SFF AMOS), Norwegian University of Science and \\ Technology (NTNU), NO-7491 Trondheim, Norway \\ * Correspondence: zhengru.ren@ntnu.no; Tel.: +47-73-413295
}

Received: 7 November 2017; Accepted: 6 December 2017; Published: 11 December 2017

\begin{abstract}
The paper presents a detailed review of the state-of-the-art research activities on structural reliability analysis of wind turbines between the 1990s and 2017. We describe the reliability methods including the first- and second-order reliability methods and the simulation reliability methods and show the procedure for and application areas of structural reliability analysis of wind turbines. Further, we critically review the various structural reliability studies on rotor blades, bottom-fixed support structures, floating systems and mechanical and electrical components. Finally, future applications of structural reliability methods to wind turbine designs are discussed.
\end{abstract}

Keywords: wind turbine; structural reliability; uncertainty; load effects; probabilistic design

\section{Introduction}

The wind industry is thriving worldwide, both onshore and offshore. Because of limited land resources, the development of offshore sites, albeit at increased costs, has become a viable alternative for many countries. In 2016, 361 offshore wind turbines (OWTs) of an average capacity rating of 4.8 megawatts (MW) per turbine were constructed in Europe [1]. Because of the favorable wind resources and shallow water conditions of the North Sea, this area accounts for almost $70 \%$ of the world's cumulative offshore capacity. Today, the unsubsidized levelized cost of energy of onshore wind energy is already lower than that of many traditional nonrenewable energy sources, e.g., natural gas, nuclear and coal [2], but offshore wind energy can still be more than twice as expensive as onshore wind energy [3].

To bring the cost of wind power to a more competitive level, reliable and economical design of wind turbines is a must. The structural design approach suggested by the international design standards $[4,5]$ is a semi-probabilistic approach, which is a slight improvement over the deterministic approach illustrated in Figure 1 (left). In this approach, a set of design load cases covering various scenarios is considered, and short-term numerical simulations of a validated wind turbine model are performed for the design load cases. To estimate higher load levels for a long-term exceedance probability, extrapolation methods are also often used [6,7]. Then, partial safety factors for loads or materials according to certain reliability levels are applied in the design check of the ultimate and fatigue limit states. These factors are calibrated by a code committee based on the long experience of building tradition or the statistical evaluation of experimental data and field observations within 
the framework of reliability theory [8]. Each turbine is subjected to the combined load effect of wind turbulence, gusts, wave loading (for OWTs) and control actions. Less frequent events including grid faults or gearbox failures may be encountered during the lifetime, as well. Based on the occurrence rate and severity of these load conditions, the design standards recommend different partial safety factors. For example, the normal load cases with power production have a higher partial safety factor than the abnormal cases with faults. Ideally, through the use of calibrated partial safety factors, a consistent level of reliability is achieved for the structural components in various load conditions. However, not all uncertainties can be captured by the partial safety factors. For novel wind turbine technologies, especially offshore floating wind turbines (FWTs), the applicability of existing partial safety factors is subject to question, because of factors such as site-specific environmental parameters, the positioning system (for FWTs), control strategies and drivetrain technologies. To account for the great uncertainties, large partial safety factors are used, which may yield a less cost-effective overdesign.
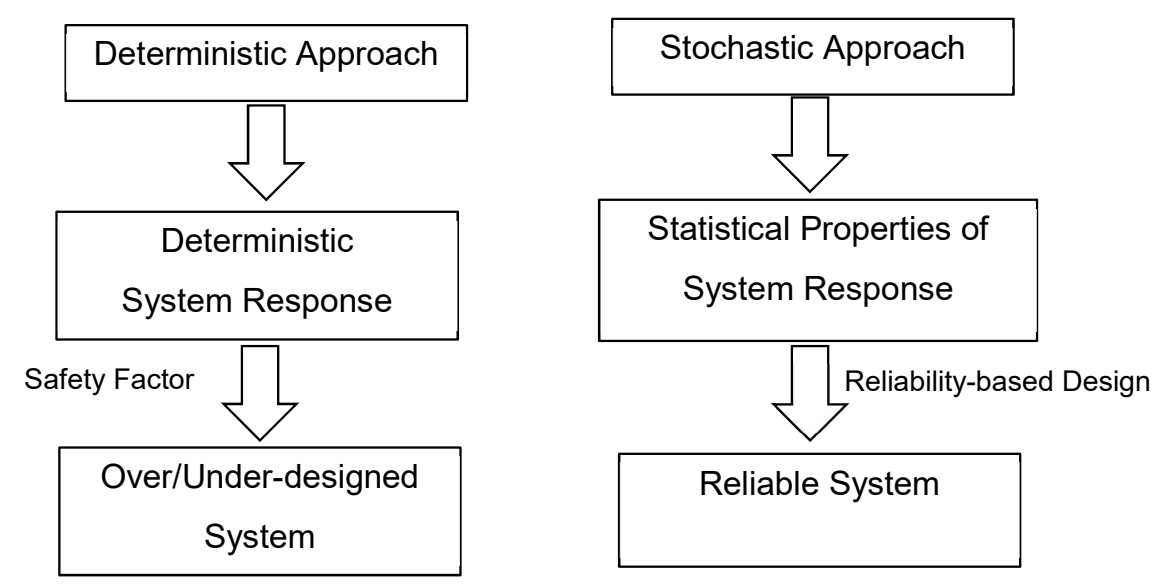

Figure 1. Design approaches for modern structures, adapted from [9].

Compared to the deterministic approach, the probabilistic (stochastic) approach improves the design as it explicitly accounts for the uncertainties related to loads, materials and analysis methods. The general design procedure is shown in Figure 1 (right). The probabilistic approach is necessary insofar as the level of uncertainty is high and has been applied in the industrial designs of aircraft structures, vehicle structures, offshore structures, as well as wind turbines. Sørensen et al. [10] presented the approach for wind turbine design. This approach involves the identification of stochastic models for the uncertain parameters and turns the design problem into a reliability-based optimization process. The aim is to design all components with a consistent level of reliability, and the wind turbine parameters are optimized such that minimal cost is achieved. A wind turbine system designed by this approach is expected to have more robust performance in response to unexpected incidents and errors.

Structural reliability analysis (SRA) is not only useful for code calibration of the partial safety factors, but also a key element of the probabilistic design approach. SRA is concerned with the calculation and prediction of the probability of limit-state violations of a structure during a reference period [9]. The formulation of limit states relating to ultimate strength, fatigue failure, structural stability or critical deflection is based on the first principles (known failure modes with physics behind them), and stochastic variables shall be included in the formulation. In a modern OWT, the analysis target can be support structures, rotor blades or mechanical components in the drivetrain. SRA is different from the classical reliability approach, which often describes the time-dependent component failure rate by the bathtub curve and relies on the operational data of wind farms for statistical analysis; see [11] for an example.

Although the development and application of structural reliability methods have lasted more than four decades, it was not until the 1990s that SRA of wind turbines started to appear in the literature, 
and most of the studies are focused on rotor blades. To the authors' knowledge, there have been over 60 academic publications on SRA of wind turbines. Yet, this number is far less than those of offshore oil and gas structures.

This study reviews the research work on SRA of wind turbines, with the hope to promote SRA in the future design of wind turbines, especially FWTs. The remainder of this paper is organized as follows. Section 2 briefly introduces the methods for SRA. Section 3 introduces the SRA procedure for modern wind turbines and identifies important areas where structural reliability methods can be applied to wind turbine design and analysis. Section 4 discusses the research work in detail in the order of wind turbine components. Section 5 envisions the future research topics. Finally, Section 6 presents the conclusion.

\section{Methodologies of Structural Reliability Analysis}

The fundamentals of SRA of wind turbines are summarized in this section. A general description of structural reliability has been addressed by a large amount of literature, e.g., [12,13].

\subsection{Definition of Structural Reliability Analysis}

Consider a wind turbine system subjected to various uncertainties, the reliability of the system is often calculated by one minus the associated probability of failure, which is defined as:

$$
P_{F}=P[g(\mathbf{X})<0]=\int_{g(\mathbf{X})<0} f_{X}(\mathbf{X}) d \mathbf{X}
$$

where $\mathbf{X} \in \mathbb{R}^{n}$ is a generic $\mathrm{n}$-dimensional random vector representing uncertainties (e.g., in loads, materials properties and geometry) of the system; the performance $g(\mathbf{X})$ is related to specific wind turbine performance (e.g., fatigue, deflection and stress/strain). $g(\mathbf{X})<0$ denotes the failure domain. As shown in Equation (1), the probability of failure $P_{F}$ is calculated by integration of the joint probability density function (PDF) of $\mathbf{X}$ over the failure domain. However, there are no closed-form/explicit solutions to Equation (1) in general due to the complexity, i.e., nonlinearity and multidimensionality of the wind turbine performances. Thus, several approximated methods have been widely used to calculate the probability of failure, such as first- and second-order reliability methods (FORM and SORM) and simulation methods (e.g., Monte Carlo simulation (MCS), importance sampling and directional simulation). The following subsections provide a summary of these methods and their applications in reliability analysis of wind turbines. Uncertainties in SRA of wind turbines are also categorized at the end of this section.

\subsection{Methods of Structural Reliability Analysis}

\subsubsection{First- and Second-Order Reliability Methods}

First- and second-order reliability methods (FORM and SORM) are two standard structural reliability methods, which are based on linear (first-order) and quadratic (second-order) approximations, respectively, of the limit state $g(\mathbf{X})=0$ tangent to the most probable point (MPP), which is closest to the origin of the variable space. The determination of this point involves nonlinear constrained optimization and is usually performed in the transformed standard normal (Gaussian) space of the original space. Figure 2 demonstrates the basic principle of FORM and SORM in a two-dimensional standard normal space. Refer to Appendix A for an example that applies FORM. 


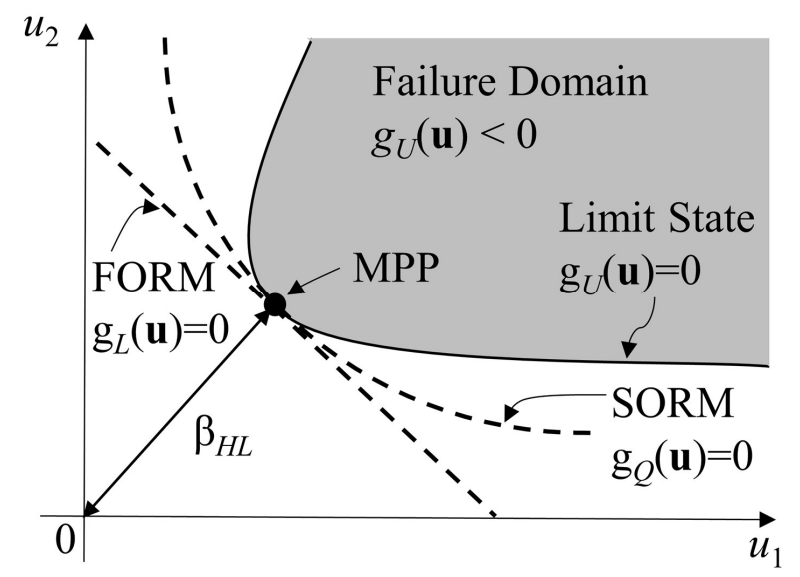

Figure 2. Schematic of first- and second-order reliability methods (FORM and SORM) in a two-dimensional standard normal space. MPP, most probable point.

For the generic n-dimensional random vector $\mathbf{X}$, the basic steps to carry out FORM/SORM include:

1. Random variable transformation: The original space of the random vector $\mathbf{X}$ is first transformed to a new $\mathbf{n}$-dimensional space $\mathbf{u}$ consisting of independent standard normal variables. The original limit state $g(\mathbf{X})=0$ is then mapped to a new limit state $g_{U}(\mathbf{u})=0$ in the $\mathbf{u}$-space.

2. MPP identification: Having the shortest distance $\beta_{H L}$ to the origin of the $\mathbf{u}$-space, the MPP is identified by using a proper nonlinear optimization algorithm.

3. Limit-state approximation: The limit state $g_{U}(\mathbf{u})=0$ is approximated by a hyperplane $g_{L}(\mathbf{u})=0$ (linear or first-order) for FORM and a hyperparaboloid $g_{Q}(\mathbf{u})=0$ (quadratic or second-order) for SORM. The approximated limit states $g_{L}(\mathbf{u})=0$ and $g_{U}(\mathbf{u})=0$ are tangent to the limit state $g_{U}(\mathbf{u})=0$ at the MPP, as shown in Figure 2.

4. Probability calculation: The failure probability using FORM is calculated as:

$$
P_{F, F O R M}=\Phi\left(-\beta_{H L}\right)
$$

where $\beta_{H L}$ is the shortest distance from the MPP to the origin of the $\mathbf{u}$-space and $\Phi(x)$ calculates the cumulative distribution function of the standard normal distribution at $x$. More sophisticated derivation is required for calculating the failure probability using SORM. For instance, Breitung's asymptotic solution is expressed as [14]:

$$
P_{F, S O R M}=\Phi\left(-\beta_{H L}\right) \prod_{i=1}^{n-1}\left(1-\beta_{H L} \kappa_{i}\right)^{-1 / 2}
$$

where $\kappa_{i}$ is the main curvatures of $g_{U}(\mathbf{u})=0$ at the MPP. Interested readers may refer to details in the literature [14-16]. Experience has shown that FORM/SORM are sufficiently accurate for engineering purposes, provided that (1) the MPP is accurately identified, (2) the limit state curve/surface at the MPP is close to being linear or quadratic and (3) no multiple MPPs exist [16].

FORM and SORM have been widely used in SRA of wind turbines. For example, Veers [17] calculated that the probability of failure with a target lifetime of 20 years is $1.8 \%$ using FORM and $2.2 \%$ using SORM in fatigue reliability analysis of a blade joint. Dong et al. [18] applied FORM in the fatigue reliability analysis of welded multi-planar tubular joints of the support structure of a fixed-jacket OWT. A comprehensive literature survey on SRA of wind turbines will be presented in Section 4 . 


\subsubsection{Simulation Reliability Methods}

Simulation reliability methods provide powerful approaches for evaluating the structural reliability of complex engineering systems including wind turbines. Compared to FORM/SORM, the simulation reliability methods treat indifferently the type and dimension of the complex problems, do not require finding the MPP or approximating the limit-state function and disregard the linearity of the limit-state function. While different simulation reliability methods exist, e.g., subset simulation [19], Latin hypercube sampling [20] and importance sampling [21], these methods more or less share the same fundamental concept of the most general simulation reliability method, MCS. Hence, we focus on the basics of MCS and its applications in SRA of wind turbines.

Suppose $\mathbf{x}_{1}, \mathbf{x}_{2}, \ldots, \mathbf{x}_{n}$ are $n$ realizations of the input random vector $\mathbf{X}$, which can be generated independently based on the joint PDF of $\mathbf{X}, f_{\mathbf{X}}(\mathbf{x})$. Let $g_{1}, g_{2}, \ldots, g_{n}$ be the output samples of $g(\mathbf{X})$ corresponding to the input $\mathbf{x}_{1}, \mathbf{x}_{2}, \ldots, \mathbf{x}_{n}$ that can be obtained by repeating the deterministic evaluation of the limit-state function. Count the number $n_{f}$ as the number of failed trialsthat are associated with negative values of the limit-state function. Then, the probability of failure using MCS is simply estimated as:

$$
P_{F, M C S}=\frac{n_{f}}{n}
$$

which approaches the exact value of $P_{F}$ when $n$ approaches infinity. In order to acquire an adequate accuracy of the approximated failure probability, it often requires a large sample size $n$, which may increase the computational burden.

MCS has also been widely used in SRA because of its simplicity and the complexity of modern wind turbines. Hu et al. [22] applied MCS to evaluate the fatigue reliability of composite wind turbines considering wind load uncertainty. Pourazarm et al. [23] utilized MCS results to evaluate three reliability methods, FORM, SORM and the weighted average reliability method for the reliability analysis of wind turbine blade failure due to flutter. Other MCS applications for SRA of wind turbines are discussed in Section 4.

\subsubsection{Other Reliability Methods}

Other reliability methods, such as the incremental wind-wave analysis (IWWA) method [24] and the peak response factor (PRF) method [25] have been developed for reliability analysis of OWT support structures under extreme loads. A comparative study of the application of different reliability analysis methods for OWT towers is presented by Teixeira et al. [26].

\subsubsection{Modeling Uncertainties in Material Properties, Loads and Load Effects of Wind Turbines}

From Section 2.1, it is clear that the structural reliability problem for a component is fully described by random variables, their probability distributions and the limit-state functions. The reliability theories are, more or less, well-established, but it is a nontrivial task in SRA to quantify various uncertainties related to loads, load effects and resistances. In general, the uncertainties can be divided into the following groups [10]:

1. Physical uncertainty related to the natural randomness of a physical quantity. For example, variation of 10-min mean wind speed in one year and uncertainty of the material properties affecting the fatigue reliability of wind turbines. The physical uncertainty is often represented by traditional distributions and incorporated into SRA of wind turbines.

2. Measurement uncertainty related to imperfect measurements. For example, the uncertainty of wind speed measurement using traditional cup anemometers would be larger than that from three-dimensional sonic anemometers. It is impossible to totally eliminate the measurement uncertainty, while using more advanced measurement techniques and instrumentation will probably reduce the measurement uncertainty and result in more accurate SRA results.

3. Statistical uncertainty related to limited sample size; for example, probabilistic S-N curves due to limited test specimens of composite materials used in wind turbine blades. Although it 
is straightforward to reduce the statistical uncertainty by increasing the test sample size, more expenditure and time in sample purchasing and testing are often caused. An alternative strategy is to develop statistical methods that can accurately quantify the uncertainty with a small sample number. In stochastic dynamic simulations, a limited number of time-domain simulations with certain durations is performed for a load case. Increasing this number will reduce the statistical uncertainty at the cost of computational time.

4. Model uncertainty related to imperfect modeling of the performances of OWTs in SRA. The model uncertainty can typically be expressed as follows:

$$
\chi=\frac{F_{\text {true }}}{F_{\text {estimated }}}
$$

where $\chi$ represents the model uncertainty related to a physical variable $F$ (e.g., aerodynamic loads). $F_{\text {true }}$ denotes the real value of this variable, and $F_{\text {estimated }}$ denotes the estimated value of this variable. Because of complicated physics and aero-hydro-servo-elastic coupling effects, high-fidelity modeling of an OWT is still a challenging task, and simplified approaches are often used. When simulating three-dimensional wind fields, Mann's model [27], the IEC Kaimal model [4] or direct numerical simulation can be used to represent the turbulent wind field at varying fidelity levels. In the aerodynamic load calculation, the blade element momentum method, vortex method and computational fluid dynamics method will produce quite different load effects [28], in addition to the uncertainties associated with airfoil data. When generating irregular waves in the time domain, either linear or nonlinear wave theories can be applied [29]; the resultant wave kinematics will vary and affect the hydrodynamic loads especially for shallow-water conditions. Morison's formula [30] or potential-flow theory is often used for hydrodynamic load calculation of offshore support structures. Then, drag and inertial coefficients related to Morison's formula or viscous effects associated with large-volume structures contribute to the uncertainties in the hydrodynamic load effects. Model uncertainty also arises when using beam elements in the finite element models to represent the complex wind turbine blades in structural dynamics problems. This type of uncertainty can be reduced by implementing advanced structural analysis methods together with high-performance computing techniques.

\section{Application of Structural Reliability Methods}

\subsection{Procedure for Structural Reliability Analysis of Wind Turbines}

Figure 3 illustrates the general procedure for simulation-based SRA of wind turbine components. First, the target wind turbine component should be selected. Second, the limit-state functions should be formulated based on failure modes of interest. The limit-state functions include random variables that represent various uncertainties, e.g., physical uncertainty. Quantification of the uncertainties often involves data measurement and statistical analysis to identify a proper joint distribution of the random variables. Then, the failure probability or reliability index can be evaluated by a reliability method. MCS is often used in conjunction with the response surface methodologies (RSMs) to alleviate computational burden. Dynamic analysis of a wind turbine system using a simplified model may be performed to obtain the global responses of the system, and analytical formulae or detailed finite element analysis (FEA) are commonly conducted to obtain the responses at the stress/strain level. At the design stage, the obtained reliability index $\beta$ is often compared against the targeted values. If the analysis results significantly deviate from the targeted values, redesign of the component is likely to follow. 


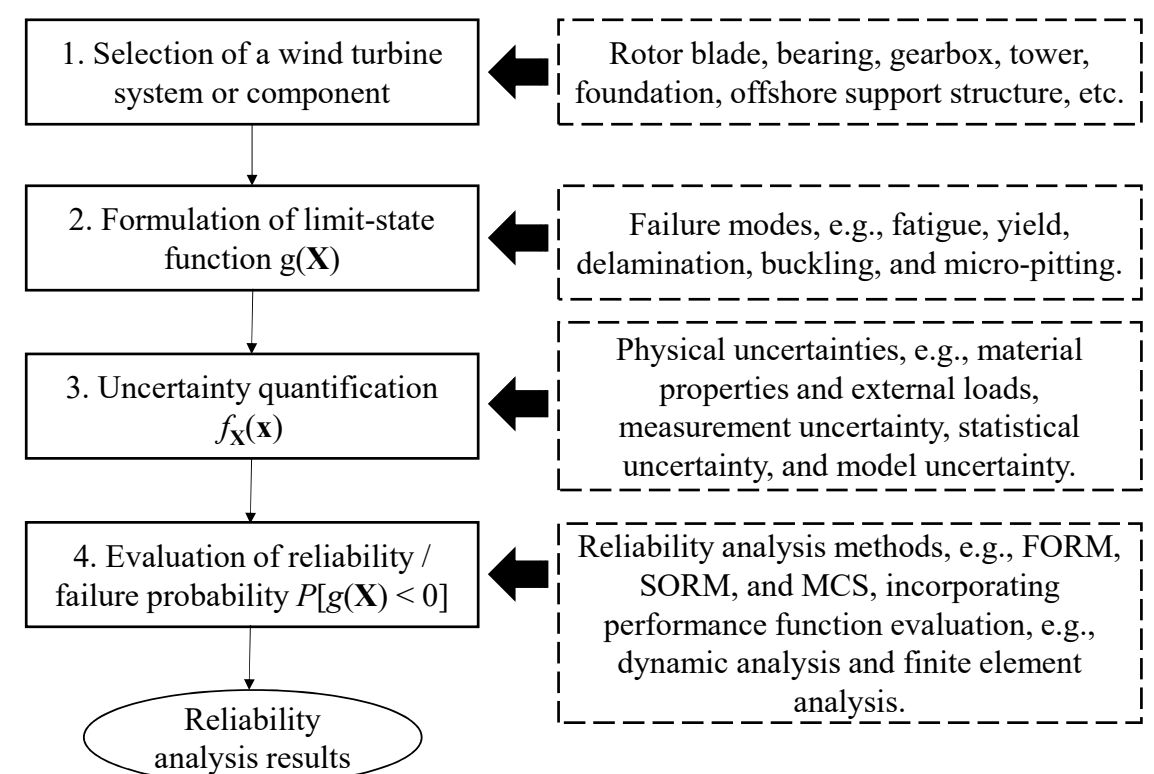

Figure 3. Flowchart for structural reliability analysis of wind turbines. MCS, Monte Carlo simulation.

\subsection{Application Areas}

Structural reliability methods provide an explicit approach to the uncertain or random nature of loads and capacities and lead to an assessment of the reliability of a structural component or an entire structure, which accounts for an optimal balance between failure consequences, material consumption and the probability of failure. It is applicable to:

- $\quad$ The design of new structures;

- The calibration of safety factors in simplified design procedures;

- The reassessment of existing structures, taking explicit account of uncertainties in deterioration due to corrosion and wear;

- Inspection planning, taking explicit account of uncertainties in inspection results from various forms of nondestructive testing;

- Decision making under uncertainty;

- Probability calculation for a wide range of events.

In the following, we elaborate on two aspects.

\subsubsection{Code Calibration for Design Standards}

Target reliabilities for a specific design have to be met in order to ensure that certain safety levels are satisfied. Reliability analysis can be used to verify that such a target reliability is achieved for a structure or structural component. Minimum values of target reliabilities depend on the consequence and nature of failure and could be calibrated against:

- Well-established cases that are known to have adequate safety;

- Safety levels established for similar existing structural design solutions that may be satisfactorily considered as being transferable;

- Accepted decision analysis techniques.

The minimum target reliability level for OWTs can be assessed by different considerations. For manned and unmanned offshore steel jacket structures for oil and gas production, maximum annual probabilities of failure on the order of $10^{-5}$ and $10^{-4}$ are generally accepted; see, e.g., DNV GL RP-C203 [31] and DNV GL RP-C210 [32]. For OWTs, a target reliability level corresponding to 
unmanned structures can be relevant. Presently, no explicit target reliability levels are given for the partial safety factors in IEC 61400-3: 2009 [5] for OWTs. However, the implicit reliability level in the design standards of OWTs by DNV [33] and GL [34] can alternatively be estimated using an available reliability analysis together with the partial safety factors recommended in these standards. A detailed estimation procedure was suggested by Marquez-Dominguez and Sørensen [35].

With a prescribed target reliability level and an available reliability method, a set of partial safety coefficients $\gamma$ can be determined, which will result in designs. The first step is to perform SRA for the initial design. Then, the design is modified, and the reliability calculation is repeated until the target reliability level is satisfied. Finally, a set of calibrated partial coefficients is obtained according to the relationships between the characteristic values of the design variables and the corresponding values at the design point.

\subsubsection{Probabilistic Methods for Inspection Planning}

An important application of probabilistic analysis methods is for risk-based inspection (RBI) planning using preposterior Bayesian decision theory, which is the basis for assessing the condition of the installation and thus forms a cornerstone in the inspection, maintenance and repair activities. For OWTs, operation and maintenance costs contribute to a substantial part of the total life cycle costs and can be expected to increase in deeper waters and harsher environments. Deterioration mechanisms such as fatigue, corrosion, wear and erosion suffer significant uncertainties. The reliability of prediction can be increased through observations of the degree of damage, especially in connection with condition-based maintenance. RBI planning can optimize the time for conditioned maintenance using observations from, e.g., condition monitoring and inspections on site. For offshore oil and gas installations, cost-effective procedures for RBI planning have been developed during the last few decades and are used at different locations worldwide; see, e.g., Moan [36], Faber et al. [37] and Sørensen et al. [38]. A detailed guideline for the use of probabilistic methods for inspection planning of fatigue cracks in jacket structures, semisubmersibles and floating production vessels is recommended in DNV GL RP-C210 [32]. For OWTs, Sørensen [39] suggested the procedures for RBI planning based on a similar theoretical basis, which can be used for gearboxes, generators, fatigue cracks, corrosion, and so forth.

\section{State-Of-The-Art Reliability Analysis of Wind Turbine Components}

\subsection{Overview}

There was limited literature on reliability analysis of wind turbines before the 1990s. Veers [17] noticed the random and uncertain parameters involved in the component design of wind turbines and first performed reliability analysis for a vertical axis wind turbine blade. Around the 2000s, Ronold et al. [40,41] applied reliability methods to analyses of rotor blades of horizontal-axis wind turbines. Afterwards, more probabilistic models of wind turbine structural components were proposed, and advanced wind turbine simulation tools came to use in SRA. In the past few years, interesting studies of reliability analysis of different subassemblies of wind turbines have been carried out. Thus, we classify the survey of the reliability analysis into the following categories: rotor blades, bottom-fixed support structures, floating systems and mechanical and electrical components. Table 1 summarizes representative failure modes of these components. The failure modes should be interpreted in a broader sense. For example, large deformation of blades does not necessarily cause damage on the blade itself, but an interference with the tower should be deemed unacceptable. The reliability problem stems from the failure modes selected, and suitable reliability methods must be selected. Table 2 summarizes some typical methods used in wind turbine applications. It appears that FORM and MCS are more frequently used than other methods. 
Table 1. List of failure modes of wind turbine components.

\begin{tabular}{|c|c|c|c|}
\hline Category & Component & Failure Modes & References \\
\hline Rotor blades & blade & $\begin{array}{l}\text { excessive bending stress, fatigue, } \\
\text { buckling, large deformation }\end{array}$ & {$[17,40,42]$} \\
\hline \multirow{4}{*}{ Bottom-fixed support structures } & tower & $\begin{array}{l}\text { excessive deformation, fatigue, yielding, } \\
\text { and plastic collapse }\end{array}$ & {$[26,43,44]$} \\
\hline & grouted connection & $\begin{array}{l}\text { fatigue, loss of axial, torsional, bending } \\
\text { moment and shear capacities }\end{array}$ & [45] \\
\hline & gravity-based foundation & loss of bearing capacity, soil failure & [46] \\
\hline & tubular structure & fatigue, large displacement & {$[18,25]$} \\
\hline \multirow{3}{*}{ Mechanical components } & shaft & fatigue & [47] \\
\hline & gear & contact fatigue, bending fatigue & [48-50] \\
\hline & bearing & $\begin{array}{l}\text { rolling contact fatigue, white } \\
\text { etching crack, skidding }\end{array}$ & [51-54] \\
\hline Electrical components & solder elements & creep and fatigue, bond wire lift-off & [55-57] \\
\hline Floating system & mooring lines & extreme load and line breakage & {$[58,59]$} \\
\hline
\end{tabular}

Table 2. Structural reliability methods used in wind turbine analysis. RSM, response surface methodology; IWWA, incremental wind-wave analysis; PRF, peak response factor.

\begin{tabular}{lll}
\hline Category & Reliability Method & References \\
\hline \multirow{3}{*}{ Rotor blades } & FORM & {$[40,41]$} \\
& MCS & {$[60,61]$} \\
& MCS with RSM & {$[42]$} \\
\hline \multirow{3}{*}{ Bottom-fixed support structures } & FORM & {$[18,35]$} \\
& MCS with RSM & {$[62,63]$} \\
& nonstandard methods, e.g., IWWA, PRF & {$[24,25,64]$} \\
\hline Mechanical and electrical components & FORM & {$[48,49,56]$} \\
\hline Floating system & MCS & {$[58,65]$} \\
\hline
\end{tabular}

\subsection{Rotor Blades}

The reliability of wind turbine rotor blades is of vital importance to the wind energy industry because of their severe loading conditions, long-term lifespan requirement and high cost. Modern horizontal-axis wind turbine blades convert the kinetic energy in wind flow to mechanical power under complex loading conditions including aerodynamic loads, gravity load, gyroscopic load and mechanical structural loads from dynamic interactions between rotor blades and other subassemblies. With these inclement loading conditions, rotor blades, as well as the whole turbine system are designed to have a lifespan of 15-20 years. In addition, each MW-scale wind turbine blade is made of tons of glass-fiber and/or carbon-fiber composite materials (e.g., NREL's 5-MW reference blade weighs over 17 tons [66]). The manufacturing cost of rotor blades accounts for about 15-20\% of the total wind turbine production cost. Considering the extreme importance of the reliability analysis of wind turbine blades, this section aims to offer a detailed survey of the state-of-the-art reliability analysis methods for the rotor blades, particularly in the following two categories:

1. Fatigue reliability analysis calculating the probability of blade fatigue life that is greater than a target lifespan under fatigue loadings.

2. Extreme reliability analysis evaluating the probability of blade performances (e.g., deflection and stress/strain) that satisfy the designed threshold under extreme loading (e.g., wind gusts).

Accurate quantification of the fatigue reliability or fatigue failure probability can be challenging because of: (1) the difficulty of an accurate fatigue life estimate under complex loading; (2) various 
inherent randomness and external uncertainties that affect the fatigue life of blades. The former challenge is mainly due to the complexity of the fatigue degradation principles of blade materials, limited information available on blade fatigue experiments and the very sophisticated fatigue analysis procedure. An early study of fatigue reliability of a blade joint was carried out by Veers [17] who described the structural reliability process as four steps: formulation that defines the failure criteria; transformation that converts correlated/uncorrelated random variables into the normal u-space; approximation that approximates the complex limit-state function in the $\mathbf{u}$-space; and computation that calculates the reliability index. For simplicity, previous blade fatigue analyses often treat wind turbine blades as typical beam-like structures [41,67-70]. From simple beam theory, explicit equations can be applied to calculate the stress/strain of wind turbine blades as a function of wind loads. For example, the normal strain can be calculated as a function of flapwise and edgewise bending moments and axial forces [71]. Fatigue stress was described in terms of the root mean square of the instantaneous stress, which was assumed to be an exponential function of wind speed [72]. Ronold et al. [41,67] calculated the stress range at the root as a ratio between the moment range and the section modulus, while the moment range was calculated as a function of 10-minute mean wind speed and other parameters. Cyclic fatigue loading for turbine blades is derived by using a time-varying stochastic wind applied on a rotating rotor and based on the traditional Miner's rule [73]. Instead of predicting the fatigue life directly, Kong et al. [68,69] evaluated whether or not the fatigue life requirement was satisfied by comparing the calculated maximum stress and the allowable fatigue stress using Spera's empirical equation [74]. Although the computational time using explicit equations for fatigue analysis is short, the detailed fatigue damage/life contour may not be investigated at a specific location on wind turbine blades. A recent study of fatigue analysis of three-dimensional composite wind turbine blades includes realistic blade model generation, variable wind load quantification, random wind field simulation, aerodynamic/aeroelastic blade analysis and advanced fatigue damage evaluation under complex stress states [22,75]. With the ever-increasing computational capability, fatigue reliability analysis using full-scale blade models has become a trend in the design, manufacture and evaluation of wind turbine blades.

In order to tackle the second challenge for fatigue reliability analysis, researchers have investigated various uncertainties, e.g., uncertainty of blade fatigue properties $[17,76]$ and uncertainty in load and resistance [22,41], and incorporated them into reliability analysis of wind turbine blades. For blades made of composite materials, the uncertainties of fatigue properties constituting S-N curves are generally greater than those of steel structures and are often represented by distributions identified from fatigue test data. An example is provided in [41], where a bivariate normal distribution was considered for the coefficients $\log _{10} K$ and $m$, and a normal distribution was considered for the residual term $e$. The SNL/MSU/DOEcomposite material fatigue database provides a large amount of fatigue test data and mechanical properties for composite materials used in wind turbine blades [77]. Abumeri et al. [78] proposed a multi-scale progress failure analysis procedure that couples composite micro- and macro-mechanics, structural analysis and probabilistic methods to simulate uncertainties from constituent materials fro the whole structure and all loading conditions. Among various uncertain sources, the inherent variability in the fatigue life as represented by the uncertainty in the residual of the $\epsilon$-N curve has been identified to be the single most important uncertainty source by Ronold et al. [41]. As an uncertain load source, wind speed variation has been widely accepted to be modeled as Weibull distributions in much of the literature (e.g., [4,34,70,79-81]). This distribution of hourly or 10-min mean wind speed has been used to determine the percentage of time that wind turbine blades (and other components) experience different mean wind speeds during their life cycles. Using this time percentage, the wind load and corresponding fatigue damage can then be calculated for each mean wind speed. By accumulating the fatigue damage for each mean speed, the total damage can be calculated based on the damage rules. However, by applying a fixed Weibull distribution, only deterministic fatigue life can be obtained because the assumed Weibull distribution is constant in different years. The fixed Weibull distribution is based on either wind turbine standards $[4,34]$ 
or measured wind data over one year at a specific location and may not be able to truly render the wind load uncertainty at different locations and in different years. Given that long-term wind speed measurements are often unavailable, statistical methods have been applied in wind prediction for fatigue reliability analysis of wind turbine blades. For example, Kulkarni et al. [82] investigated three forecasting models (Markov chain, Kalman filter and autoregressive integrated moving average) and developed a long-term wind speed pattern used in the structural and fatigue analysis of a small horizontal-axis wind turbine composite blade. In addition to the mean wind speed, the fluctuations in the wind speed about the short-term mean naturally have a major impact on the blade fatigue reliability. Considering the wind fluctuations, Ronold et al. [41] assumed that the turbulence intensity followed a lognormal distribution. In order to facilitate the fatigue reliability analysis of wind turbine blades surviving realistic wind loads, Hu et al. [22] developed a dynamic wind load uncertainty model that can capture the uncertainty of distribution parameters of both mean wind speed and turbulence intensity to represent the wind load variations over a larger spatiotemporal range based on measured wind data.

Reliability analysis of wind turbine blades under extreme loads is also an important topic to which many wind turbine blade designers and wind farm operators have been paying attention. Blade responses under extreme loads could cause significant damage to the turbine itself and maintenance personnel or any people nearby the turbine. For example, an extraordinary blade deflection induced by edgewise and flapwise bending or buckling of the blade may cause catastrophic failures by hitting the turbine tower. For designing reliable wind turbine blades, wind turbine standards (e.g., $[4,34])$ have provided guidelines to calculate the extreme loading (e.g., extreme operating gust), which are followed by many researchers. For example, ultimate strength and critical deflection of a $40 \mathrm{~m}$-long and $2 \mathrm{MW}$-rated wind turbine blade were implemented into a multi-objective structural optimization procedure [83]. Toft et al. [60] presented a framework for modeling defects in wind turbine blade and particularly investigated the effect of defect distribution on the reliability of the blades in the ultimate limit state. According to their findings, a larger reduction in the reliability was observed if the delamination defects occur in clusters rather than in random distributions. Bacharoudis et al. [42] performed a reliability assessment of the strength and elastic stability of a composite rotor blade designed according to the IEC 61400-1 standard. A combination of RSM and MCS was applied in their reliability analysis. The rotor blade reliability under extreme loads is closely related to uncertainty sources, e.g., uncertainty in airfoil aerodynamic characteristics and uncertainty in the extreme turbulence model used for load calculation. For example, Abdallah et al. [84] found that the uncertainties in aerodynamic static lift and drag coefficients had a tangible reduction in both the extreme load safety factors and the dimension of structural components when exposed to extreme loading conditions. In another article, Abdallah et al. [61] demonstrated that advanced load alleviation control systems could contribute to improved structural reliability by reducing the magnitude and scatter of the extreme loads. As an increasing number of OWTs is deployed, extreme offshore environmental conditions have also been investigated in the reliability analysis and design of wind turbine blades, as well as the whole turbine system. An interesting study by Hallowell and Myers estimated the turbulent wind and irregular sea states using a catalog of synthetic hurricanes, which provide tens of thousands of realizations for one year of potential hurricane activity [65]. One of the difficulties that extreme reliability analysis of wind turbine blades faces is the lack of validation cases for the reliability analysis results due to the rare records of blade failures under extreme loadings. Experimental testing of down-scaled blade models or high-fidelity computer-based simulation of blades under extreme loads may promise to alleviate this difficulty. 


\subsection{Bottom-Fixed Support Structures}

\subsubsection{Onshore Structures}

For onshore wind turbines, towers are the only type of support structures; they are mostly made of steel or concrete. The seismic loads appear to be more of a concern for the research community, and the term "fragility analysis" is used. Fragility analyses were initially used in earthquake engineering for evaluating the vulnerability of structures [85]. Such an analysis involves computing the probability of damage over a range of potential loading intensities, and researchers have employed the fragility curves for onshore and OWT support structures beyond the scope of seismic loading. Nuta et al. [86] developed a framework for determining the probability of damage of onshore wind turbine towers at various levels of seismic damage. Implicit FEA and incremental dynamic analysis were performed for the steel tower of a 1.65-MW onshore wind turbine in parked conditions. Myers et al. [87] assessed the fragility of the tubular tower of a 2.4-MW wind turbine with respect to yielding. Incremental dynamic analysis using a finite element model was conducted, and fragilities were presented as a function of ground motion intensity and frequency content. Quilligan et al. [88] selected the hub-height wind speed as the intensity measure and examined the fragility of a 5-MW onshore wind turbine. A range of typical tower heights was considered, and fragility curves of steel and concrete towers were compared. Mensah and Dueñas-Osorio [89] showed the positive effect of tuned liquid column dampers on improving the fragility of a 5-MW onshore wind turbine. Hu et al. [90,91] proposed novel seismic-based methods to monitor the health condition of onshore wind turbine components.

\subsubsection{Offshore Structures}

Support structures are the main components investigated in SRA of OWTs. The dominant types of support structures are monopiles, gravity-based foundations and jackets; see Figure 4. Compared to traditional offshore structures subjected to wave loads alone, these support structures experience the combined load effects of wind and waves.
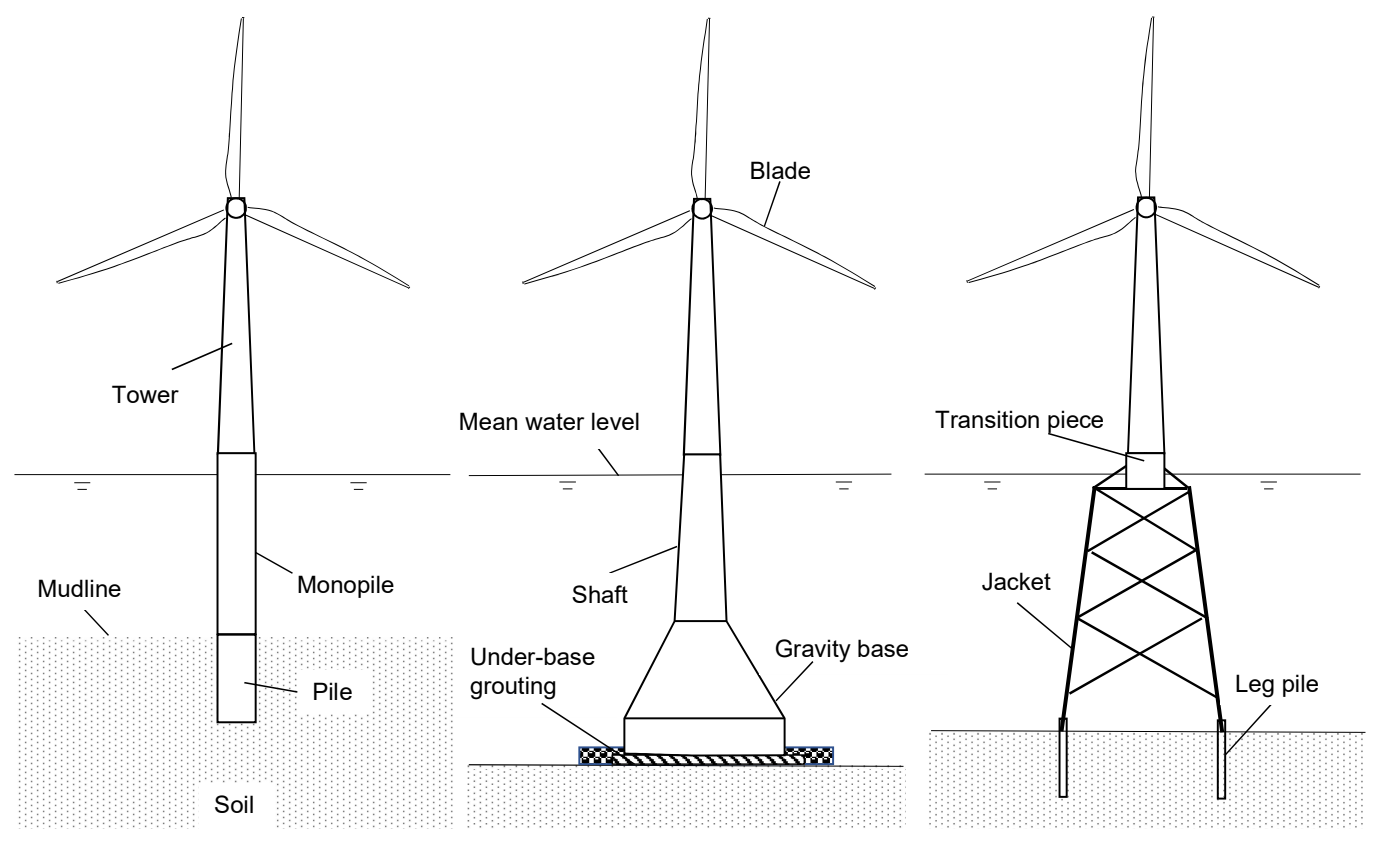

Figure 4. Schematic of support structures of bottom-fixed offshore wind turbines (from left to right: monopile, gravity-based and jacket foundations).

Tarp-Johansen [92] formulated the ultimate limit state of a pile structure, performed the reliability analysis by FORM and proposed a simplified method for evaluating the structural responses under the 
combined loads in storm conditions. The aerodynamic, hydrodynamic and material uncertainties are addressed. Adjustments are made in regards to the hydrodynamic uncertainty model, and phase shift is ignored between the arrival of wind and wave storms. Similarly, Tarp-Johansen et al. [93] studied the partial safety factors and the characteristic values of bottom-fixed OWTs under extreme wind and wave loads; the level of structural reliability indicated by the design standard IEC 61400-3 was also discussed. Sørensen [94] performed reliability-based investigation of the required fatigue safety factors for the fatigue design of steel structures of OWTs. Reliability models were formulated for the cases with wind only and wave only, and fatigue design factors and partial safety factors were calibrated considering the effect of inspections during the design life. In another work, Márquez-Domínquez and Sørensen [35] performed similar calibrations and considered more inspection methods. Although these calibrations were based on a limited number of wind turbines and simplified load conditions, there is a close link to design standards of offshore steel structures. Vahdatirad et al. [46] performed reliability analysis of a gravity-based foundation for wind turbines. A probabilistic finite element model was used to analyze the bearing capacity of a surface footing on soil. The reliability analysis can be used to calibrate the code-based design procedure. Yeter et al. [95] conducted fatigue reliability analysis of jacket-type OWTs by using FORM. The limit-state function was developed based on the Dirlik probability density function. The approach is based on calculations in the frequency domain, and the wind-induced loads are simplified as a transfer function. The validity of this simplification is questionable, because aerodynamic damping from the rotor side cannot be handled by such an approach. Using the fracture mechanics approach, Yeter et al. [96,97] also performed fatigue reliability analysis of welded tubular structures of a jacket-type OWT, but the aerodynamic loads and relevant uncertainties were ignored in these works.

Most of the aforementioned studies consider simple models for the wind turbine loads. In the past 10-15 years, a variety of aero-hydro-servo-elastic simulation tools [98-100] suitable for OWT analysis were developed and validated, and there is a trend to apply these tools for dynamic analysis to facilitate the establishment of probabilistic models. In addition, FEA may be involved when component stresses/strains, which are usually included in the limit-state functions, cannot be calculated in a straightforward manner. Dong et al. [18] performed fatigue reliability analysis of the welded tubular joints of a jacket OWT. In Dong's work, HAWC2 [99] and USFOS [101] were used to assess the load effects of aerodynamic and hydrodynamic loads in the time domain, and 400 environmental conditions were considered. The SRA was based on fracture mechanics analysis of crack growth, and the probability of failure was calculated by FORM. Various uncertainties related to aerodynamic and hydrodynamic loads, long-term stress distribution and corrosion and inspection were identified and evaluated. Muskulus and Schafhirt [102] performed both ultimate and fatigue limit-state analyses of monopile and jacket support structures for 5-MW OWTs. The time-domain calculation was done by Fedem [103], and the approach is comparable to the one used by [18] insofar as precalculated aerodynamic loads were exerted on the structure, apart from the instantaneous hydrodynamic loads. The effect of the uncertainties in soil stiffness and aerodynamic damping was assessed by MCS with importance sampling. Compared to the monopile structure, the jacket structure was found to be more robust to uncertainties and modeling error. When evaluating the ultimate limit states in reliability analysis, more than one load component can be involved, and combining univariate maxima is overconservative. To address this issue, Muskulus [104] proposed the use of the Pareto-optimal load vector for reliability assessment. A representative limit-state function from the NORSOKstandard [105] was selected, and an application of this approach to monopile- and jacket-type OWTs was shown. Morató et al. [63] evaluated the reliability of a monopile wind turbine using limit-state functions to represent structural yield and local buckling failure. Approximately 200 dynamic simulations were conducted in FAST based on DLC1.3 of IEC 61400-3, and the kriging model was applied to approximate the von Mises stress and overturning moment. The proposed framework can be extended to other types of OWT support structures. 
Some researchers have successfully applied SRA in the design and optimization of OWTs. Lee et al. [45] conducted design load analysis of a monopile wind turbine using GH Bladed. Ultimate limit state and fatigue limit state were established for the grouted connections. The optimization problem was formulated aiming at minimizing the structural mass while satisfying the limit-state functions. Both deterministic and probabilistic optimization approaches were considered. In the probabilistic optimization approach, Latin hypercube sampling was used to reduce the number of simulations. In parallel, Yang et al. [62] performed dynamic analysis of the tripod support structure of an OWT using FAST. The kriging surrogate model was used to reduce the number of FEA. Three limit-state functions related to stress, tower displacement and natural frequency were considered in the design constraints, but it is not clear at which safety level the design is targeted.

Recently, several less established methods have been applied in the reliability analysis. Wei et al. [24] employed FAST to calculate the aerodynamic forces and performed IWWA on two 5-MW wind turbines: one mounted on a monopile support structure and the other mounted on a jacket support structure. The IWWA is similar to the pushover analysis used by the offshore oil and gas industry $[106,107]$, and the support structures fail when the demand base shear exceeds the capacity. However, only static analyses were conducted, and few uncertainties were considered, causing an especially high reliability index for the monopile structure ( $\beta \approx 5.4$ for a 20-year service life). In a work following that, Wei et al. [24] applied the IWWA to assess the effect of load directionality on the structural reliability of a jacket support structure. Similarly, Kim and Lee [25] used GH Bladed [100] in the thrust force calculation and performed reliability analysis for the jacket-type support structure of a 5-MW OWT. The peak-over-threshold method was applied to find the extreme value distribution, and RSM was used to find the relation between variables. The limit-state function was defined using the allowable displacement of support structures at the seabed, and the reliability index was found using FORM. The approach is efficient, because the dynamic response is not directly calculated, but estimated by multiplying the static response with a constant dynamic amplification factor. Because of this simplification, this approach should be exercised with caution for structures with nonlinear behavior. Kim et al. [64] performed seismic fragility analysis of a 5-MW monopile-type OWT. Static pushover analyses were performed to obtain the critical displacement for the wind turbine. Wei et al. [108] did a performance evaluation of a jacket-type OWT using a static pushover approach, as well. The environmental hazard models include extreme wave height and extreme speed. Ciampoli and Petrini [109] discussed various sources of loading uncertainties of OWTs in the framework of performance-based engineering. This framework is analogous to the probabilistic design approach [10]. Mardfekri and Gardoni [110] developed simplified probabilistic models for the deformation, shear and moment demands for monopile-type OWTs subjected to wind, waves and currents. The probabilistic models account for the nonlinear soil-structure interaction and inherent uncertainties. The fragilities were expressed as a function of wind speed or wave height. In a follow-up work [111], a probabilistic framework was proposed to evaluate the reliability of OWTs subjected to multiple hazards including extreme wind and seismic loads.

\subsection{Floating Systems}

The solution to the challenge of deep-water offshore wind power is FWTs. Following the successful installation and operation of Hywind Demo in 2009, a range of FWT concepts has been deployed at the prototype level. Figure 5 shows three main categories of floating support structures: spar, semisubmersible and tension leg platform (TLP). It is evident that mooring systems will affect the global motions and operational performance of FWTs. Although multiple designs of floating systems have been proposed, most of the published literature used the deterministic approach without considering uncertainties; see [112-114]. Among the few works that utilize SRA, Wandji et al. [58] used HAWC2 [99] and ABAQUS [115] for reliability-based design of the universal joint and mooring lines of a semi-floater substructure supporting a 10-MW wind turbine. The ultimate limit states were addressed in the reliability analysis, where uncertainty variables are used to represent various uncertainties in 
dynamic responses, aerodynamic parameters, climate statistics, and so forth. Although engineering assumptions were made for the random variables, the approach is of value for the development of new floating structures. Hallowell et al. [59] assessed the reliability of mooring lines and anchors of a FWT farm, which is composed of semisubmersible FWTs with multi-line anchors. Dynamic simulations using FAST [98] and MOORDYN [116] were conducted to obtain the load distributions under operational and extreme environmental conditions, and lognormal fragility functions were assumed for the distribution of mooring and anchor capacities. It was found that for the multi-line case, the probability of failure of mooring lines and anchors is increased. This framework may be further extended for reliability assessment of wind farms.

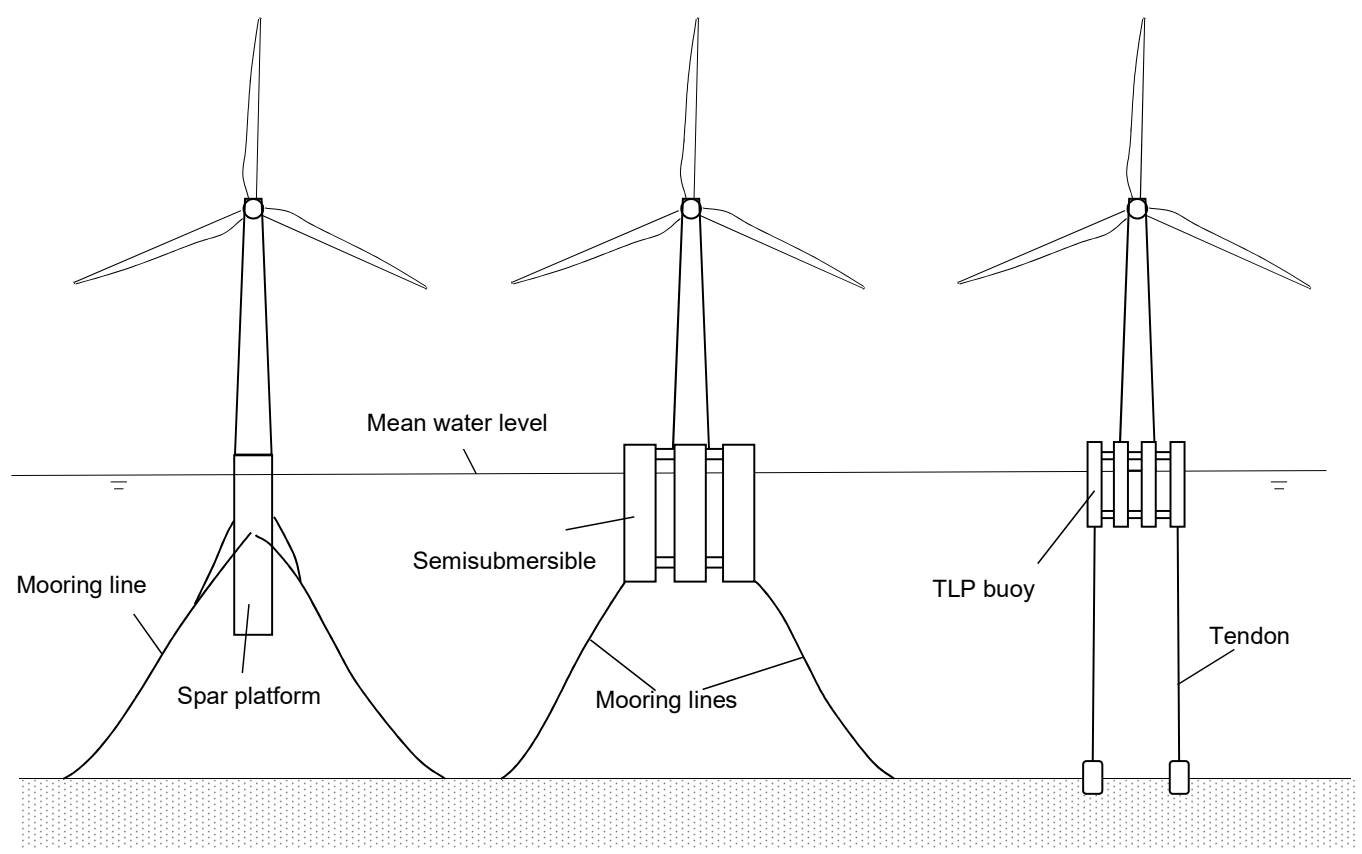

Figure 5. Schematic of floating wind turbine systems (from left to right: spar, semisubmersible and tension leg platforms (TLP)).

\subsection{Mechanical and Electrical Components}

As illustrated in Figure 6, a large number of mechanical components is installed in a traditional wind turbine with gear transmission. The reliability of mechanical components in the drivetrain of wind turbines has been an issue since the inception of the wind industry. Even for onshore wind turbines, significant system repairs are often required before reaching their 20-year lifetime. As mentioned in [51], the majority of gearbox failures appear to initiate in the bearings and later advance into the gear teeth. Drivetrain components are typically exposed to complex loading conditions. Traditionally, the reliability assessment of those components is done by classical reliability techniques, and the failure rate is used as the basic measure [11]. Such an approach often relies on measurement or test data and lacks insight into the physical nature of structural degradation and failure. To evaluate the drivetrain design loads and understand the load effects in operational, parked or fault conditions of onshore wind turbines, various studies on dynamic response analysis [53,117-122] have been carried out using finite element or multibody simulation codes. For example, Dong et al. [119] performed dynamic response analysis of a 750-kW wind turbine drivetrain and analyzed the dynamic gear contact forces. Jiang et al. [53] also performed multibody simulation of the same drivetrain and focused on the dynamic loads on the planetary bearings. Zhao and Ji [123] proposed a four-degree-of-freedom dynamic model and studied the dynamic responses of both the gears and bearings of a wind turbine gearbox. Wei et al. [124] derived a torsional vibration model for the dynamic response analysis of a gearbox transmission system considering the influence of uncertain parameters. 


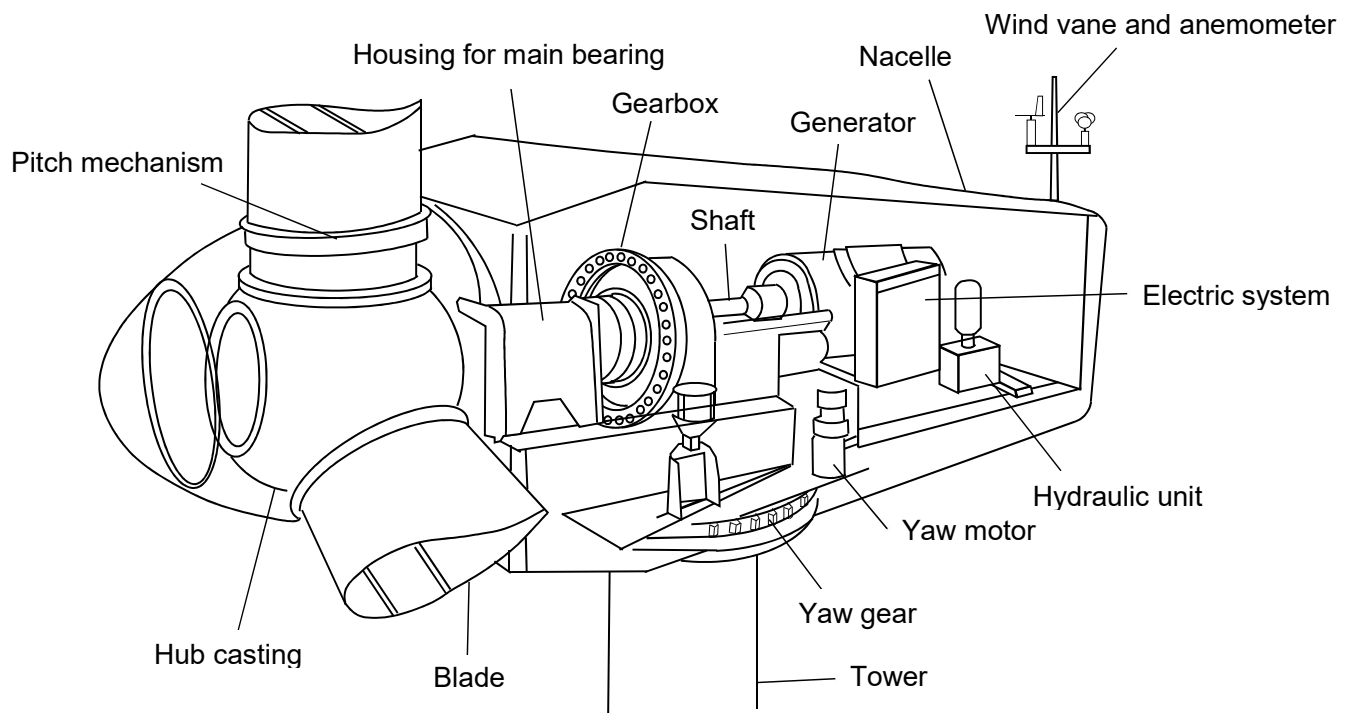

Figure 6. Schematic of the mechanical components of a traditional wind turbine.

Dynamic response analysis or test data is an important prerequisite to SRA of mechanical components including shafts, gears and bearings, and proper reliability-based design will, to some extent, avoid premature failures of the mechanical components from known failure modes, e.g., rolling contact fatigue. Tarp-Johansen [47] conducted an interesting project on reliability assessment of three wind turbine components (hub, main shaft and main frame). In the work, model uncertainties relating to wind turbine dynamic simulation and component FEA were clearly addressed, and limit-state functions were established based on fatigue failure criteria using the bin-wise expected lifetimes. The calibration procedure of the partial safety factors was also presented. Dong et al. [48] described a method for gear contact fatigue reliability analysis of wind turbines and considered a $750-\mathrm{kW}$ stall-regulated land-based wind turbine in the study. First, global dynamic response analysis of the wind turbine was performed in the time domain. Second, the main-shaft torque was used as an input to the multibody simulation, and time series of gear contact forces were obtained. Then, the long-term distribution of the gear contact pressure can be found by curve fitting, and the limit-state function was formulated based on fracture mechanics of crack growth. Finally, the effects of material properties and inspection and repair were assessed. Nejad et al. [49] also presented a method for long-term fatigue reliability analysis of wind turbine drivetrains using a similar analysis procedure. However, unlike Dong et al. who considered a surface pitting model for the contact fatigue problem, Nejad et al. used a conservative equation suggested by ISO 6336-6 [50] to relate the gear transmitted load to the stress range from gear root bending. The limit-sate function was also formulated differently by the S-N curve approach. Because the NREL 5-MW pitch-regulated land-based wind turbine was used in the analysis, the obtained reliability indices of the gear components were representative of utility scale wind turbines. Rafsanjani and Sørensen [125] examined two stochastic models based on Weibull and lognormal distribution functions for modeling fatigue failures of cast iron components including the main bearing and main shaft. The study used the test data of ductile cast iron for statistical analysis and reliability assessment and focused on the uncertainties present in the limit-state function: model uncertainties, statistical uncertainties and geometrical size effect. Furthermore, Rafsanjani and Sørensen [126] extracted loads of the main shaft from numerical simulations of a 5-MW wind turbine and compared the annual reliability indices using different uncertainty models.

Figure 7 gives an overview of the failure distribution of wind turbine components. The data are based on the wind turbine operators' regular reports of 1500 German wind turbines over 15 years. As shown, the annual failure rates of the power electronics of wind turbines are considerably higher than other components, and the research of reliability in power electronics is shifting from a statistically-based approach towards a physics-of-failure approach to achieve higher safety levels [57]. 
Kostandyan and Sørensen [55] developed a probabilistic damage model for the crack propagation process of a power semiconductor device. The model describes the initial accumulated plastic strain from temperature mean and temperature range and can be used to estimate the fatigue damage and reliability levels in electrical components. Based on this damage model, Kostandyan and Sørensen [56] performed a reliability assessment of solder joints in power electronics components considering the physical, model and measurement uncertainties. A more comprehensive, but similar study is presented in [127], where a temperature range factor was introduced to meet the designed reliability requirements. The advantages of the physics-based approach in reliability assessment are that better understanding of the failure mechanism is achieved and various sources of uncertainties are explicitly considered. However, only one failure mechanism was considered in the work, and multidisciplinary studies are needed to fully address the issue.

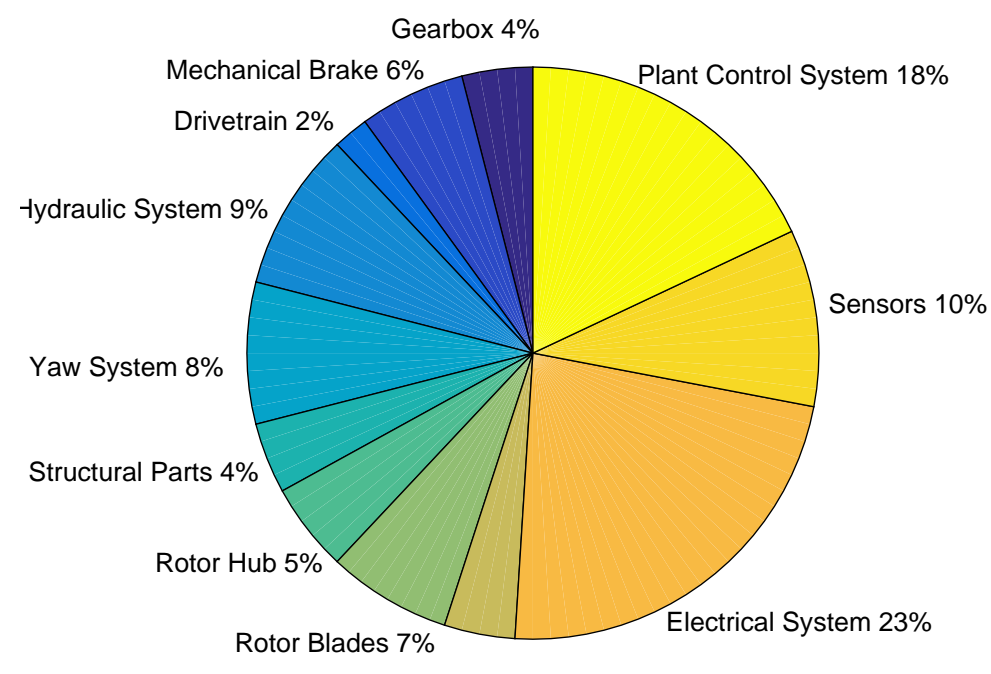

Generator $4 \%$

Figure 7. Distribution of the number of failures (34,582 in total) [128].

\section{Research Prospect}

It can be seen that most of the relevant studies are focused on rotor blades and bottom-fixed support structures of wind turbines. In this section, we envisage the future application of structural reliability methods to wind turbine design and analysis.

- $\quad$ Floating wind turbines:

In recent years, the research and development of offshore wind energy has shifted from bottom-fixed OWTs in shallow waters to FWTs in deeper waters where benefits are present such as improved wind conditions, reduced wave loading and lesser visual impact. Various designs of FWT concepts have been proposed, and spar buoys, semisubmersibles and tension leg platforms are dominant types of support structures. The research focus is still on horizontal-axis wind turbines; see [129-137]. Clearly, many of these support structures and mooring systems are not designed based on the probabilistic approach, and great structural redundancies exist. As the reliability analysis methods and procedures for offshore structures are quite mature [138-140], it is expected that these methods will be extended and applied in the response-based optimal design of FWTs. However, it is still challenging, but critical to properly assess the model uncertainties in the load effects due to the controller behavior [141-143], site conditions [144], aerodynamic modeling $[28,145]$ and load extrapolation methods [61,146].

- Drivetrain components: 
Most of the modern wind turbines use gearboxes as the medium for power transmission. The gearbox components, including bearings and gears, used to be designed by manufacturers that have limited knowledge of the system loads and responses. Consequently, failures of the gearbox components contribute substantially to the downtime of wind turbines. Since 2007, significant numerical modeling and dynamometer testing efforts have been done to investigate the root causes of component failures $[51,52,54]$. The physics-based reliability analysis has potential to be applied in bearing and gear design. For specific failure modes such as micropitting, white-etching area cracks and rolling contact fatigue, the limit-state functions can be formulated, and the mechanical components can be designed for a consistent reliability level. Because the damage development of the mechanical components is influenced by the operational conditions including unsteady wind, braking, generator misalignment, lubricants and grid faults [147], there is a need to address the uncertainties related to these factors. In addition to the traditional gear transmission, other types of drivetrain technologies including direct drive [148] and hydraulic transmission $[149,150]$ have also appeared on the market, and the reliability of these novel technologies remains an open question.

- Reliability-based design optimization:

Reliability-based design optimization (RBDO) is one promising extension of SRA. Studies by $[22,45,62]$ show that RBDO brings more reliable and cost-effective designs than the deterministic approaches do. By using efficient sampling methods and RSMs, the computational costs of the optimization problem are also acceptable. Therefore, it is envisaged that RBDO will be more widely applied in the design process of wind turbine components. Ideally, if all structural components are designed according to a consistent reliability level, then the failure rates of OWTs are expected to decrease.

\section{Conclusions}

This paper summarizes the research work in the field of wind turbine reliability analysis in the past three decades. We introduce the fundamentals of structural reliability analysis and present the general procedure of the analysis for wind turbines. Then, we discuss in detail relevant works on rotor blades, bottom-fixed structures, floating structures and mechanical and electrical components. The conclusions are as follows:

- Research on the reliability analysis of wind turbines is still focused on the rotor blades and bottom-fixed support structures, and there is strong potential to apply reliability methods in the design of floating wind turbines and the drivetrain components.

- When there is a lack of test data, the state-of-the-art approach for response-based probabilistic design includes coupled dynamic simulation for the global motion and finite element analysis for the detailed structural analysis. Some novel analysis approaches (e.g., incremental wind-wave analysis method and peak response factor method) do not involve dynamic analysis and should be exercised with caution. Most of the limit-state functions can be formulated based on the ultimate limit state or fatigue limit state. First- and second-order reliability methods or Monte Carlo simulations together with response surface methodologies are often used to evaluate the reliability index.

- Quantification of uncertainties is a critical element in reliability analysis. There are challenges especially for novel wind turbine structures. To facilitate the reliability-based design of wind turbines, future work is greatly needed for assessing the modeling uncertainties.

Acknowledgments: This work has been financially supported by the Research Council of Norway granted through the Department of Marine Technology and the Centre for Research-based Innovation of Marine Operations (SFI MOVE) at NTNU.

Author Contributions: All authors contributed substantially to the discussion and writing of the paper.

Conflicts of Interest: The authors declare no conflict of interest. 


\section{Appendix A. Worked Example Using First-Order Reliability Method}

The following example is adapted from [151]. For support structures of offshore wind turbines, fatigue failure is a common failure mode, and the limit-state function may be expressed as:

$$
g_{X}(\mathbf{X})=\Delta-D
$$

where $\Delta$ is the fatigue damage at failure and $D$ is the fatigue damage in a period $T$. By assuming Weibull distributed stress ranges and using the S-N approach, $D$ can be described by:

$$
D=\frac{N_{0}}{k} A^{m} \Gamma\left(\frac{m}{B}\right)
$$

where $N_{0}$ is the total number of cycles in the long-term period, $m$ and $k$ are material parameters of the S-N curve, $S_{0}$ is the stress range exceeded with a probability $1 / N_{0}, B$ is a shape parameter of the Weibull distribution and $A$ is a function of $S_{0}$ and $N_{0}$. Then, the limit-state function can be simplified and reformulated as:

$$
g_{X}(\mathbf{X})=\ln X_{1}-m \cdot \ln X_{2}+\ln X_{3}-\ln k
$$

where $X_{1}$ is related to $\Delta$ and $X_{2}$ and $X_{3}$ are random and independent variables related to $A$ and $B$, respectively. Distributions of these variables are listed in Table A1. Through this simple exercise, we will illustrate how to calculate the reliability index $(\beta)$ and the failure probability $\left(P_{F}\right)$ by FORM.

Table A1. Characteristics of the variables in the limit-state function.

\begin{tabular}{cccc}
\hline Variable & Mean Value $\left(\mu_{\boldsymbol{X}_{\boldsymbol{i}}}\right)$ & Coefficient of Variation $\left(\boldsymbol{V}_{\boldsymbol{X}_{\boldsymbol{i}}}\right)$ & Distribution \\
\hline$m$ & 3.0 & 0 & Deterministic \\
$k$ & $1 \times 10^{6}$ & 0 & Deterministic \\
$X_{1}$ & 1 & 0 & Deterministic \\
$X_{2}$ & 300 & 0.3 & Lognormal \\
$X_{3}$ & $5 \times 10^{13}$ & 0.4 & Lognormal \\
\hline
\end{tabular}

To transform the random variable into the $\mathbf{u}$-space, we can express the transformation function as:

$$
U_{i}=\frac{\ln X_{i}-\mu_{\ln X_{i}}}{\sigma_{\ln X_{i}}}
$$

By using this transformation, the limit-state function can be expressed as:

$$
\begin{aligned}
g_{U}(\mathbf{U}) & =-m \cdot\left(\sigma_{\ln X_{2}} U_{2}+\mu_{\ln X_{2}}\right)+\left(\sigma_{\ln X_{3}} U_{3}+\mu_{\ln X_{3}}\right)-\ln k \\
& =-0.881 U_{2}+0.385 U_{3}+0.672
\end{aligned}
$$

Thus, the standard linear form of $g_{U}(U)$ can be normalized as:

$$
\begin{aligned}
g_{U}^{*}(\mathbf{U}) & =-\frac{0.881}{\sqrt{0.881^{2}+0.385^{2}}} U_{2}+\frac{0.385}{\sqrt{0.881^{2}+0.385^{2}}} U_{2}+\frac{0.672}{\sqrt{0.881^{2}+0.385^{2}}} \\
& =-0.916 U_{2}+0.400 U_{3}+0.699 \\
& =-\alpha^{T} \mathbf{U}+\beta
\end{aligned}
$$

where $\alpha^{T}=\left[\begin{array}{lll}0.0 & -0.916 & 0.400\end{array}\right], \beta=0.699$. In this case, $\beta$ is solved without iteration because of the linear limit-state function. Based on Equation (2), the failure probability is calculated as:

$$
\begin{aligned}
P_{F, F O R M} & =\Phi(-0.699) \\
& =0.242
\end{aligned}
$$




\section{References}

1. Pineda, I.; Tardieu, P. The European Offshore Wind Industry-Key Trends and Statistics 2016. Available online: https://windeurope.org/about-wind/statistics/offshore/european-offshore-windindustry-key-trends-and-statistics-2016/ (accessed on 1 June 2017).

2. Lazard Ltd. Lazard's Levelized Cost of Energy Analysis_-Version 10.0; Lazard Ltd.: Hamilton, Bermuda, 2016.

3. Moné, C.; Hand, M.; Bolinger, M.; Rand, J.; Heimiller, D.; Ho, J. 2015 Cost of Wind Energy Review; Technical Report NREL/TP-6A20-66861; National Renewable Energy Laboratory: Golden, CO, USA, 2017.

4. International Electrotechnical Commission. IEC 61400-1: Wind Turbines Part 1: Design Requirements; International Electrotechnical Commission: Geneva, Switzerland, 2005.

5. International Electrotechnical Commission. IEC 61400-3: Wind Turbines_Part 3: Design Requirements for Offshore Wind Turbines; International Electrotechnical Commission: Geneva, Switzerland, 2009.

6. Freudenreich, K.; Argyriadis, K. Wind turbine load level based on extrapolation and simplified methods. Wind Energy 2008, 11, 589-600.

7. Sichani, M.T.; Nielsen, S.; Naess, A. Failure probability estimation of wind turbines by enhanced Monte Carlo method. J. Eng. Mech. 2011, 138, 379-389.

8. EN 1990. Eurocode-Basis of Structural Design; CEN/TC 250; Thomas Telford: London, UK, 2002.

9. Choi, S.K.; Grandhi, R.V.; Canfield, R.A. Reliability-Based Structural Design; Springer Science \& Business Media: Berlin, Germany, 2006.

10. Sørensen, J.D.; Toft, H.S. Probabilistic design of wind turbines. Energies 2010, 3, 241-257.

11. Tavner, P.; Xiang, J.; Spinato, F. Reliability analysis for wind turbines. Wind Energy 2007, 10, 1-18.

12. Ditlevsen, O.; Madsen, H.O. Structural Reliability Methods; Wiley: New York, NY, USA, 1996; Volume 178.

13. Melchers, R.E. Structural Reliability: Analysis and Prediction; Horwood: Chichester, UK, 1987.

14. Breitung, K. Asymptotic approximations for multinormal integrals. J. Eng. Mech. 1984, 110, 357-366.

15. Hohenbichler, M.; Rackwitz, R. Improvement of second-order reliability estimates by importance sampling. J. Eng. Mech. 1988, 114, 2195-2199.

16. Rahman, S.; Wei, D. A univariate approximation at most probable point for higher-order reliability analysis. Int. J. Solids Struct. 2006, 43, 2820-2839.

17. Veers, P. Fatigue Reliability of Wind Turbine Components; Report; Sandia National Labs.: Albuquerque, NM, USA, 1990.

18. Dong, W.; Moan, T.; Gao, Z. Fatigue reliability analysis of the jacket support structure for offshore wind turbine considering the effect of corrosion and inspection. Reliab. Eng. Syst. Saf. 2012, 106, 11-27.

19. Au, S.K.; Beck, J.L. Estimation of small failure probabilities in high dimensions by subset simulation. Probab. Eng. Mech. 2001, 16, 263-277.

20. Olsson, A.; Sandberg, G.; Dahlblom, O. On Latin hypercube sampling for structural reliability analysis. Struct. Saf. 2003, 25, 47-68.

21. Mori, Y.; Ellingwood, B.R. Time-dependent system reliability analysis by adaptive importance sampling. Struct. Saf. 1993, 12, 59-73.

22. Hu, W.; Choi, K.; Cho, H. Reliability-based design optimization of wind turbine blades for fatigue life under dynamic wind load uncertainty. Struct. Multidiscip. Optim. 2016, 54, 953-970.

23. Pourazarm, P.; Caracoglia, L.; Lackner, M.; Modarres-Sadeghi, Y. Perturbation methods for the reliability analysis of wind-turbine blade failure due to flutter. J. Wind Eng. Ind. Aerodyn. 2016, 156, 159-171.

24. Wei, K.; Arwade, S.R.; Myers, A.T. Incremental wind-wave analysis of the structural capacity of offshore wind turbine support structures under extreme loading. Eng. Struct. 2014, 79, 58-69.

25. Kim, D.H.; Lee, S.G. Reliability analysis of offshore wind turbine support structures under extreme ocean environmental loads. Renew. Energy 2015, 79, 161-166.

26. Teixeira, R.; O'Connor, A.; Nogal, M. Comparative analysis of the probabilistic methods to estimate the probability of failure of offshore wind turbine towers. In Proceedings of the Civil Engineering Research in Ireland Conference (CERI 2016), Galway, Ireland, 29-30 August 2016; pp. 29-30.

27. Mann, J. Wind field simulation. Probab. Eng. Mech. 1998, 13, 269-282.

28. Hansen, M.O.; Madsen, H.A. Review paper on wind turbine aerodynamics. J. Fluids Eng. 2011, $133,114001$.

29. Det Norske Veritas. DNV-RP-C205: Environmental Conditions and Environmental Loads; Det Norske Veritas: Oslo, Norway, 2010. 
30. Morison, J.; Johnson, J.; Schaaf, S. The force exerted by surface waves on piles. J. Pet. Technol. 1950, 2, 149-154.

31. Det Norske Veritas \& Germanischer Lloyd SE. DNVGL-RP-C203: Fatigue Design of Offshore Steel Structures; Det Norske Veritas \& Germanischer Lloyd SE: Oslo, Norway, 2016.

32. Det Norske Veritas \& Germanischer Lloyd SE. DNVGL-RP-C210: Probabilistic Methods for Planning of Inspection for Fatigue Cracks in Offshore Structures; Det Norske Veritas \& Germanischer Lloyd SE: Oslo, Norway, 2015.

33. Det Norske Veritas. Offshore Standard DNV-OS-J101: Design of Offshore Wind Turbine Structures; Technical Report; Det Norske Veritas: Oslo, Norway, 2010.

34. Germanischer Lloyd. Guideline for the Certification of Wind Turbines; GL Renewables Certification: Hamburg, Germany, 2010.

35. Márquez-Domínguez, S.; Sørensen, J.D. Fatigue reliability and calibration of fatigue design factors for offshore wind turbines. Energies 2012, 5, 1816-1834.

36. Moan, T. Reliability-based management of inspection, maintenance and repair of offshore structures. Struct. Infrastruct. Eng. 2005, 1, 33-62.

37. Faber, M.; Engelund, S.; Sørensen, J.D.; Bloch, A. Simplified and generic risk based inspection planning. In Proceedings of the OMAE 2000 Conference, New Orleans, LA, USA, 14-17 February 2000.

38. Sørensen, J.D.; Faber, M.H. Generic inspection planning for steel structures. In International Conferene on Structural Safety and Reliability; Balkema Publishers, AA/Taylor \& Francis: Rotterdam, The Netherlands, 2002.

39. Sørensen, J.D. Framework for risk-based planning of operation and maintenance for offshore wind turbines. Wind Energy 2009, 12, 493-506.

40. Ronold, K.O.; Larsen, G.C. Reliability-based design of wind-turbine rotor blades against failure in ultimate loading. Eng. Struct. 2000, 22, 565-574.

41. Ronold, K.O.; Wedel-Heinen, J.; Christensen, C.J. Reliability-based fatigue design of wind-turbine rotor blades. Eng. Struct. 1999, 21, 1101-1114.

42. Bacharoudis, K.C.; Philippidis, T.P. A probabilistic approach for strength and stability evaluation of wind turbine rotor blades in ultimate loading. Struct. Saf. 2013, 40, 31-38.

43. Jin, X.; Ju, W.; Zhang, Z.; Guo, L.; Yang, X. System safety analysis of large wind turbines. Renew. Sustain. Energy Rev. 2016, 56, 1293-1307.

44. Albermani, F.; Kitipornchai, S.; Chan, R. Failure analysis of transmission towers. Eng. Fail. Anal. 2009, 16, 1922-1928.

45. Lee, Y.S.; Choi, B.L.; Lee, J.H.; Kim, S.Y.; Han, S. Reliability-based design optimization of monopile transition piece for offshore wind turbine system. Renew. Energy 2014, 71, 729-741.

46. Vahdatirad, M.J.; Griffiths, D.; Andersen, L.V.; Sørensen, J.D.; Fenton, G. Reliability analysis of a gravity-based foundation for wind turbines: a code-based design assessment. Géotechnique 2014, 64, 635-645.

47. Tarp-Johansen, N.J. Examples of Fatigue Lifetime and Reliability Evaluation of Larger Wind Turbine Components; Technical Report; Risø National Laboratory: Roskilde, Denmark, 2003.

48. Dong, W.; Moan, T.; Gao, Z. Gear Contact Fatigue Reliability Analysis for Wind Turbines Under Stochastic Dynamic Conditions Considering Inspection and Repair. In Proceedings of the ASME 2014 33rd International Conference on Ocean, Offshore and Arctic Engineering, San Francisco, CA, USA, 8-13 June 2014.

49. Nejad, A.R.; Gao, Z.; Moan, T. On long-term fatigue damage and reliability analysis of gears under wind loads in offshore wind turbine drivetrains. Int. J. Fatigue 2014, 61, 116-128.

50. BSI. Calculation of Load Capacity of Spur and Helical Gears-Part 6: Calculation of Service Life Under Variable Load; British Standards Institution: London, UK, 2006.

51. Musial, W.; Butterfield, S.; McNiff, B. Improving Wind Turbine Gearbox Reliability. In Proceedings of the European Wind Energy Conference, Milan, Italy, 7 May 2007; pp. 7-10.

52. Keller, J.; Link, H.F.; Guo, Y.; LaCava, W.; McNiff, B.P. Gearbox Reliability Collaborative Phase 1 and 2: Testing and Modeling Results; Technical Report; National Renewable Energy Laboratory: Golden, CO, USA, 2011.

53. Jiang, Z.; Xing, Y.; Guo, Y.; Moan, T.; Gao, Z. Long-term contact fatigue analysis of a planetary bearing in a land-based wind turbine drivetrain. Wind Energy 2015, 18, 591-611.

54. Keller, J.; Guo, Y.; Sethuraman, L. Gearbox Reliability Collaborative Investigation of Gearbox Motion and High-Speed-Shaft Loads; Technical Report; National Renewable Energy Laboratory: Golden, CO, USA, 2016.

55. Kostandyan, E.E.; Sørensen, J.D. Reliability assessment of solder joints in power electronic modules by crack damage model for wind turbine applications. Energies 2011, 4, 2236-2248. 
56. Kostandyan, E.E.; Sørensen, J.D. Reliability of wind turbine components-Solder elements fatigue failure. In Proceedings of the Annual on Reliability and Maintainability Symposium (RAMS), Reno, NV, USA, 23-26 January 2012; pp. 1-7.

57. Blaabjerg, F.; Ma, K.; Zhou, D. Power electronics and reliability in renewable energy systems. In Proceedings of the 2012 IEEE International Symposium on Industrial Electronics (ISIE), Hangzhou, China, 28-31 May 2012; pp. 19-30.

58. Wandji, W.N.; Natarajan, A.; Dimitrov, N. Development and design of a semi-floater substructure for multi-megawatt wind turbines at 50+ m water depths. Ocean Eng. 2016, 125, 226-237.

59. Hallowell, S.T.; Arwade, S.R.; Fontana, C.M.; DeGroot, D.J.; Diaz, B.D.; Landon, M.E. Reliability of Mooring Lines and Shared Anchors of Floating Offshore Wind Turbines. In Proceedings of the 27th International Ocean and Polar Engineering Conference, San Francisco, CA, USA, 25-30 June 2017.

60. Toft, H.S.; Branner, K.; Berring, P.; Sørensen, J.D. Defect distribution and reliability assessment of wind turbine blades. Eng. Struct. 2011, 33, 171-180.

61. Abdallah, I.; Natarajan, A.; Sørensen, J.D. Influence of the control system on wind turbine loads during power production in extreme turbulence: Structural reliability. Renew. Energy 2016, 87, 464-477.

62. Yang, H.; Zhu, Y.; Lu, Q.; Zhang, J. Dynamic reliability based design optimization of the tripod sub-structure of offshore wind turbines. Renew. Energy 2015, 78, 16-25.

63. Morató, A.; Sriramula, S.; Krishnan, N. Reliability Analysis of Offshore Wind Turbine Support Structures Using Kriging Models. In Risk, Reliability and Safety: Innovating Theory and Practice; Walls, L., Revie, M., Bedford, B., Eds.; Taylor \& Francis Group: Didcot, London, UK, 2017.

64. Kim, D.H.; Lee, S.G.; Lee, I.K. Seismic fragility analysis of 5 MW offshore wind turbine. Renew. Energy 2014, 65, 250-256.

65. Hallowell, S.; Myers, A. Site-specific variability of load extremes of offshore wind turbines exposed to hurricane risk and breaking waves. Wind Energy 2017, 20, 143-157.

66. Jonkman, J.; Butterfield, S.; Musial, W.; Scott, G. Definition of a 5-MW Reference Wind Turbine for Offshore System Development; Report; National Renewable Energy Laboratory: Golden, CO, USA, 2009.

67. Ronold, K.O.; Christensen, C.J. Optimization of a design code for wind-turbine rotor blades in fatigue. Eng. Struct. 2001, 23, 993-1004.

68. Kong, C.; Bang, J.; Sugiyama, Y. Structural investigation of composite wind turbine blade considering various load cases and fatigue life. Energy 2005, 30, 2101-2114.

69. Kong, C.; Kim, T.; Han, D.; Sugiyama, Y. Investigation of fatigue life for a medium scale composite wind turbine blade. Int. J. Fatigue 2006, 28, 1382-1388.

70. Griffith, D.T.; Ashwill, T.D. The Sandia 100-Meter All-Glass Baseline Wind Turbine Blade: SNL100-00; Report No. SAND2011-3779; Sandia National Laboratories: Albuquerque, NM, USA, 2011.

71. Fossum, P.K.; Frøyd, L.; Dahlhaug, O.G. Design and fatigue performance of large utility-scale wind turbine blades. J. Sol. Energy Eng. 2013, 135, 031019.

72. Winterstein, S.R.; Veers, P. A Numerical Analysis of the Fatigue and Reliability of Wind Turbine Components; Technical report, No. SAND94-2459; Sandia National Laboratories: Albuquerque, NM, USA, 2000.

73. Hu, W.; Park, D.; Choi, D. Structural optimization procedure of a composite wind turbine blade for reducing both material cost and blade weight. Eng. Optim. 2013, 45, 1469-1487.

74. Spera, D.A. Wind Turbine Technology: Fundamental Concepts of Wind Turbine Engineering; ASME Press: New York, NY, USA, 1994; Volume 3.

75. Hu, W.; Choi, K.; Zhupanska, O.; Buchholz, J.H. Integrating variable wind load, aerodynamic, and structural analyses towards accurate fatigue life prediction in composite wind turbine blades. Struct. Multidiscip. Optim. 2016, 53, 375-394.

76. Veldkamp, H.F. Chances in Wind Energy: A Probalistic Approach to Wind Turbine Fatigue Design; Delft University of Technology: Delft, The Netherlands, 2006.

77. Mandell, J.; Samborsky, D. SNL/MSU/DOE Composite Material Fatigue Database Mechanical Properties of Composite Materials for Wind Turbine Blades Version 23.0; Montana State University: Bozeman, MT, USA, 2014.

78. Abumeri, G.; Paquette, J.; Abdi, F. Durability and Reliability of Wind Turbine Composite Blades Using Robust Design Approach. In Proceedings of the SAMPE Tech 2011 Conference and Exhibition, Fort Worth, TX, USA, 18-20 October 2011; pp. 17-20. 
79. Shokrieh, M.M.; Rafiee, R. Simulation of fatigue failure in a full composite wind turbine blade. Compos. Struct. 2006, 74, 332-342.

80. Manwell, J.F.; McGowan, J.G.; Rogers, A.L. Wind Energy Explained: Theory, Design and Application; John Wiley \& Sons: Hoboken, NJ, USA, 2010.

81. Burton, T.; Jenkins, N.; Sharpe, D.; Bossanyi, E. Wind Energy Handbook; John Wiley \& Sons: Hoboken, NJ, USA, 2011.

82. Kulkarni, P.A.; Hu, W.; Dhoble, A.S.; Padole, P.M. Statistical wind prediction and fatigue analysis for horizontal-axis wind turbine composite material blade under dynamic loads. Adv. Mech. Eng. 2017, 9, 1-26.

83. Hu, W.; Han, I.; Park, S.C.; Choi, D.H. Multi-objective structural optimization of a HAWT composite blade based on ultimate limit state analysis. J. Mech. Sci. Technol. 2012, 26, 129-135.

84. Abdallah, I.; Natarajan, A.; Sørensen, J.D. Impact of uncertainty in airfoil characteristics on wind turbine extreme loads. Renew. Energy 2015, 75, 283-300.

85. Kafali, C.; Grigoriu, M. Seismic fragility analysis. In 9th ASCE Specialty Conference on Probabilistic Mechanics and Structural Reliability; Curran: New York, NY, USA, 2004.

86. Nuta, E.; Christopoulos, C.; Packer, J.A. Methodology for seismic risk assessment for tubular steel wind turbine towers: application to Canadian seismic environment. Can. J. Civ. Eng. 2011, 38, 293-304.

87. Myers, A.; Gupta, A.; Ramirez, C.; Chioccarelli, E. Evaluation of the seismic vulnerability of tubular wind turbine towers. In Proceedings of the 15th World Conference on Earthquake Engineering, Lisbon, Portugal, 24-28 September 2012.

88. Quilligan, A.; O'Connor, A.; Pakrashi, V. Fragility Analysis of Steel and Concrete Wind Turbine Towers. Eng. Struct. 2012, 36, 270-282.

89. Mensah, A.F.; Dueñas-Osorio, L. Improved reliability of wind turbine towers with tuned liquid column dampers (TLCDs). Struct. Saf. 2014, 47, 78-86.

90. Hu, W.; Pryor, S.; Letson, F.; Barthelmie, R. Use of Seismic Analyses for the Wind Energy Industry. J. Sol. Energy Eng. 2017, 139, 051007.

91. Hu, W.; Barthelmie, R.; Letson, F.; Pryor, S. A new seismic-based condition monitoring approach for wind turbines. Nat. Energy 2018, Under review.

92. Tarp-Johansen, N.J. Partial safety factors and characteristic values for combined extreme wind and wave load effects. Trans. ASME-N-J. Sol. Energy Eng. 2005, 127, 242-252.

93. Tarp-Johansen, N.; Manwell, J.; McGowan, J. Application of design standards to the design of offshore wind turbines in the US. In Proceedings of the Offshore Technology Conference, Houston, TX, USA, 1-4 May 2006.

94. Sørensen, J.D. Reliability-based calibration of fatigue safety factors for offshore wind turbines. In Proceedings of the Twenty-First International Offshore and Polar Engineering Conference, Maui, HI, USA, 19-24 June 2011.

95. Yeter, B.; Garbatov, Y.; Soares, C.G. System reliability of a jacket offshore wind turbine subjected to fatigue. In Progress in the Analysis and Design of Marine Structures; Taylor \& Francis Group: London, UK, 2017.

96. Yeter, B.; Garbatov, Y.; Soares, C.G. Fatigue reliability of an offshore wind turbine supporting structure accounting for inspection and repair. In Analysis and Design of Marine Structures; Soares, G., Shenoi, Eds.; Taylor \& Francis Group: London, UK, 2015; pp. 737-747.

97. Yeter, B.; Garbatov, Y.; Soares, C.G. Reliability of Offshore Wind Turbine Support Structures Subjected to Extreme Wave-Induced Loads and Defects. In Proceedings of the ASME 2016 35th International Conference on Ocean, Offshore and Arctic Engineering, Busan, South Korea, 19-24 June 2016.

98. Jonkman, J.M.; Buhl, M.L., Jr. FAST User's Guide-Updated August 2005; Technical Report; National Renewable Energy Laboratory: Golden, CO, USA, 2005.

99. Larsen, T.J.; Hansen, A.M. How 2 HAWC2, the User's Manual; Technical Report; Risø National Laboratory: Roskilde, Denmark, 2007.

100. Bossanyi, E. GH Bladed User Manual; Technical Report; Garrad Hassan Bladed: Bristol, UK, 2009.

101. Søreide, T.H.; Amdahl, J.; Eberg, E.; Holmås, T.; Hellan, Ø. A Computer Program for Progressive Collapse Analysis of Steel Offshore Structures; USFOS: Gosen, Norway, 1993.

102. Muskulus, M.; Schafhirt, S. Reliability-based design of wind turbine support structures. In Proceedings of the Symposium on Reliability of Engineering System, Hangzhou, China, 15-17 Octorber 2015.

103. Fedem AS. Fedem User's Guide, Release 7.0.3; Technical Report; Fedem AS: Trondheim, Norway, 2013.

104. Muskulus, M. Pareto-optimal evaluation of ultimate limit states in offshore wind turbine structural analysis. Energies 2015, 8, 14026-14039. 
105. NORSOK Standard N-004. Design of Steel Structures; Standards Norway: Lyaker, Norway, 2004.

106. Mathisen, J.; Ronold, K.O.; Sigurdsson, G. Probabilistic modelling for reliability analysis of jackets. In Proceedings of the 23rd International Conference on Offshore Mechanics and Arctic Engineering, Vancouver, BC, Canada, 20-25 June 2004.

107. API RP2A. Recommended Practice for Planning, Designing and Constructing Fixed Offshore Platforms; American Petroleum Institute (API): Washington, DC, USA, 2005.

108. Wei, K.; Arwade, S.; Myers, A.; Hallowell, S.; Hajjar, J.; Hines, E.; Pang, W. Toward performance-based evaluation for offshore wind turbine jacket support structures. Renew. Energy 2016, 97, 709-721.

109. Ciampoli, M.; Petrini, F. Performance-based design of offshore wind turbines. In Earth and Space 2010: Engineering, Science, Construction, and Operations in Challenging Environments; American Society of Civil Engineers: Reston, VA, USA, 2010; pp. 2063-2078.

110. Mardfekri, M.; Gardoni, P. Probabilistic demand models and fragility estimates for offshore wind turbine support structures. Eng. Struct. 2013, 52, 478-487.

111. Mardfekri, M.; Gardoni, P. Multi-hazard reliability assessment of offshore wind turbines. Wind Energy 2015, $18,1433-1450$.

112. Lefebvre, S.; Collu, M. Preliminary design of a floating support structure for a 5MW offshore wind turbine. Ocean Eng. 2012, 40, 15-26.

113. Brommundt, M.; Krause, L.; Merz, K.; Muskulus, M. Mooring system optimization for floating wind turbines using frequency domain analysis. Energy Procedia 2012, 24, 289-296.

114. Benassai, G.; Campanile, A.; Piscopo, V.; Scamardella, A. Ultimate and accidental limit state design for mooring systems of floating offshore wind turbines. Ocean Eng. 2014, 92, 64-74.

115. Hibbitt, Karlsson \& Sorensen. ABAQUS/Standard User's Manual; Hibbitt, Karlsson \& Sorensen: Providence, RI, USA, 2001; Volume 1.

116. Hall, M. MoorDyn-Users Guide; Department of Mechanical Engineering, University of Maine: Orono, ME, USA, 2015.

117. Peeters, J. Simulation of Dynamic Drive Train Loads in a Wind Turbine; Katholieke Universiteit Leuven: Leuven, Belgium, 2006.

118. Heege, A.; Betran, J.; Radovcic, Y. Fatigue load computation of wind turbine gearboxes by coupled finite element, multi-body system and aerodynamic analysis. Wind Energy 2007, 10, 395-413.

119. Dong, W.; Xing, Y.; Moan, T. Time domain modeling and analysis of dynamic gear contact force in a wind turbine gearbox with respect to fatigue assessment. Energies 2012, 5, 4350-4371.

120. Dong, W.; Xing, Y.; Moan, T.; Gao, Z. Time domain-based gear contact fatigue analysis of a wind turbine drivetrain under dynamic conditions. Int. J. Fatigue 2013, 48, 133-146.

121. Xing, Y.; Moan, T. Multi-body modelling and analysis of a planet carrier in a wind turbine gearbox. Wind Energy 2013, 16, 1067-1089.

122. Nejad, A.R.; Jiang, Z.; Gao, Z.; Moan, T. Drivetrain load effects in a 5-MW bottom-fixed wind turbine under blade-pitch fault condition and emergency shutdown. J. Phys. Conf. Ser. 2016, 753, 112011.

123. Zhao, M.; Ji, J. Dynamic analysis of wind turbine gearbox components. Energies 2016, 9, 110.

124. Wei, S.; Zhao, J.; Han, Q.; Chu, F. Dynamic response analysis on torsional vibrations of wind turbine geared transmission system with uncertainty. Renew. Energy 2015, 78, 60-67.

125. Rafsanjani, H.M.; Sørensen, J.D. Stochastic models of defects in wind turbine drivetrain components. In Multiscale Modeling and Uncertainty Quantification of Materials and Structures; Springer: Berlin, Germany, 2014; pp. 287-298.

126. Rafsanjani, H.M.; Sørensen, J.D. Reliability analysis of fatigue failure of cast components for wind turbines. Energies 2015, 8, 2908-2923.

127. Kostandyan, E.E.; Sørensen, J.D. Physics of failure as a basis for solder elements reliability assessment in wind turbines. Reliab. Eng. Syst. Saf. 2012, 108, 100-107.

128. Hahn, B.; Durstewitz, M.; Rohrig, K. Reliability of Wind Turbine-Experiences of 15 Years with 1500 WTs; Institut für Solare Energieversorgungstechnik (ISET): Hesse, Germany, 2005.

129. Wayman, E.N.; Sclavounos, P.; Butterfield, S.; Jonkman, J.; Musial, W. Coupled dynamic modeling of floating wind turbine systems. In Proceedings of the Offshore Technology Conference, Houston, TX, USA, 1-4 May 2006. 
130. Jonkman, J. Definition of the Floating System for Phase IV of OC3; Technical Report; National Renewable Energy Laboratory: Golden, CO, USA, 2010.

131. Robertson, A.; Jonkman, J.; Masciola, M.; Song, H.; Goupee, A.; Coulling, A.; Luan, C. Definition of the Semisubmersible Floating System for Phase II of OC4; Technical Report; National Renewable Energy Laboratory: Golden, CO, USA, 2014.

132. Roddier, D.; Peiffer, A.; Aubault, A.; Weinstein, J. A generic 5 MW WINDFLOAT for numerical tool validation \& comparison against a generic spar. In Proceedings of the ASME 30th International Conference on Ocean, Offshore and Arctic Engineering, Rotterdam, The Netherlands, 19-24 June 2011.

133. Luan, C.; Gao, Z.; Moan, T. Modeling and Analysis of a Semi-Submersible Wind Turbine With a Central Tower With Emphasis on the Brace System. In Proceedings of the 32nd International Conference on Ocean, Offshore and Arctic Engineering, Nantes, France, 9-14 June 2013; Paper No. OMAE2013-10408.

134. Myhr, A.; Nygaard, T.A. Load reductions and optimizations on tension-leg-buoy offshore wind turbine platforms. In Proceedings of the Twenty-Second International Offshore and Polar Engineering Conference, Rhodes, Greece, 17-22 June 2012.

135. Bachynski, E.E.; Moan, T. Design considerations for tension leg platform wind turbines. Mar. Struct. 2012, $29,89-114$.

136. Adam, F.; Steinke, C.; Dahlhaus, F.; Großmann, J. GICON®-TLP for wind turbines—Validation of calculated results. In Proceedings of the Twenty-Third International Offshore and Polar Engineering Conference, Anchorage, AK, USA, 30 June-5 July 2013.

137. Paulsen, U.S.; Madsen, H.A.; Hattel, J.H.; Baran, I.; Nielsen, P.H. Design optimization of a 5 MW floating offshore vertical-axis wind turbine. Energy Procedia 2013, 35, 22-32.

138. Vázquez-Hernández, A.; Ellwanger, G.; Sagrilo, L. Long-term response analysis of FPSO mooring systems. Appl. Ocean Res. 2011, 33, 375-383.

139. Fontaine, E.; Orsero, P.; Ledoux, A.; Nerzic, R.; Prevosto, M.; Quiniou, V. Reliability analysis and Response Based Design of a moored FPSO in West Africa. Struct. Saf. 2013, 41, 82-96.

140. Mousavi, M.E.; Gardoni, P. A simplified method for reliability-and integrity-based design of engineering systems and its application to offshore mooring systems. Mar. Struct. 2014, 36, 88-104.

141. Bossanyi, E. Individual blade pitch control for load reduction. Wind Energy 2003, 6, 119-128.

142. Larsen, T.J.; Hanson, T.D. A method to avoid negative damped low frequent tower vibrations for a floating, pitch controlled wind turbine. J. Phys. Conf. Ser. 2007, 75, 012073.

143. Jiang, Z.; Moan, T.; Gao, Z. A comparative study of shutdown procedures on the dynamic responses of wind turbines. J. Offshore Mech. Arct. Eng. 2015, 137, 011904.

144. Haldar, S.; Basu, D. Effect of Climate Change on the Reliability of Offshore Wind Turbine Foundations. In Geo-Chicago 2016; American Society of Civil Engineers: Reston, VA, USA, 2016; pp. 407-417.

145. De Vaal, J.; Hansen, M.O.L.; Moan, T. Validation of a vortex ring wake model suited for aeroelastic simulations of floating wind turbines. J. Phys. Conf. Ser. 2014, 555, 012025.

146. Li, Q.; Gao, Z.; Moan, T. Modified environmental contour method to determine the long-term extreme responses of a semi-submersible wind turbine. Ocean Eng. 2017, 142, 563-576.

147. Stadler, K.; Stubenrauch, A. Premature Bearing Failures in Wind Gearboxes and White Etching Cracks; Power Transmission Engineering: Chicago, IL, USA, 2014.

148. Sethuraman, L.; Xing, Y.; Gao, Z.; Venugopal, V.; Mueller, M.; Moan, T. A 5MW direct-drive generator for floating spar-buoy wind turbine: Development and analysis of a fully coupled Mechanical model. Proc. Inst. Mech. Eng. Part A J. Power Energy 2014, 228, 718-741.

149. Jiang, Z.; Yang, L.; Gao, Z.; Moan, T. Numerical simulation of a wind turbine with a hydraulic transmission system. Energy Procedia 2014, 53, 44-55.

150. Yang, L.; Jiang, Z.; Gao, Z.; Moan, T. Dynamic Analysis of a Floating Wind Turbine with a Hydraulic Transmission System. In Proceedings of the Twenty-Fifth International Ocean and Polar Engineering Conference, Kona, HI, USA, 21-26 June 2015.

151. Moan, T. MR8206 Structural Reliability; Lecture Notes; Department of Marine Technology, Norwegian University of Science and Technology: Trondheim, Norway, 2011.

(C) 2017 by the authors. Licensee MDPI, Basel, Switzerland. This article is an open access article distributed under the terms and conditions of the Creative Commons Attribution (CC BY) license (http://creativecommons.org/licenses/by/4.0/). 